\title{
A shortage risk mitigation model for multi-agency coordination in logistics planning
}

\author{
Oscar Rodríguez-Espíndola* \\ Aston Business School, OIM Group \\ Aston Triangle, Birmingham B4 7ET, United Kingdom \\ *Corresponding author: o.rodriguez-espindola@aston.ac.uk \\ Douglas Alem \\ University of Edinburgh Business School \\ 29 Buccleuch Place, EH8 9JS, Edinburgh, United Kingdom \\ Lucas Pelegrin da Silva \\ Production Engineering Department, Federal University of São Carlos \\ Sorocaba, Brazil
}

\begin{abstract}
We introduce a two-stage stochastic program to handle typical disaster preparedness activities under uncertainty from a multi-agency perspective. The model explicitly takes into account the number of people without healthcare attention, relief aid, and shelter support. We build a function that represents the total number of people at risk of not receiving proper humanitarian assistance using a bi-objective approach in which expected logistics costs are also minimized. The benefit of our approach is assessed through real flood cases in Mexico in which GIS analysis was used to enhance data gathering and to provide risk maps that could be potentially used by policy-makers in practical settings. The overall results suggest that sheltering decisions have to be closely coordinated with the management of material and human resources to avoid an increased number of people deprived of attention and relief aid. The Pareto Frontier also reveals that some solutions exhibit a quite interesting trade-off, e.g., it is possible to improve the overall relief assistance by almost $17 \%$ at the expense of less than $14 \%$ in the logistics costs

Keywords: Disaster relief; Humanitarian logistics; Preparedness management;

Multi-agency coordination; Two-stage stochastic programming;
\end{abstract}


Acknowledgements. The second author thanks the support of the British Academy via BA/Leverhulme Small Research Grant SRG18R1 \180939, the UEBS First Grant Venture Fund, as well as the São Paulo State Research Support Foundation (FAPESP) Grant 2016/12165-2. 


\section{INTRODUCTION}

As the magnitude and impact of disasters are rather difficult to be predicted prior to an event, decision-making becomes challenging because of the uncertainty in demand and supply (Jia et al, 2007). The number of victims is unknown, the number of available skilled workers is uncertain, and even the amount of relief ultimately depends on the economic situation and/or political agreements. Preparedness activities based on imprecise data can thus result in unrealistic or even infeasible solutions, since there is no guarantee that the disaster will resemble previous ones and there is no knowledge about the conditions of the aftermath.

Collaborative efforts ranging from local to the international level are mechanisms to manage complex environmental problems. The fact that disaster operations are often engaged by a relatively large number of relief organizations (Nolte et al, 2012; Li et al, 2018), especially governmental agencies, further complicates an already complex situation because of the diverse goals, values, and access to resources of the participants (Thompson and Duintjer Tebbens, 2016). Governmental agencies have to liaise with a central coordinator which directs their activities (Margaret B. and Marilyn M., 2006). Poor interaction among these organizations can exacerbate the impact of disasters on communities (Haimes, 2012), because it can lead to both shortage and/or excess of supply (Auf der Heide and Irwin, 1989).

Moynihan (2008) argues that relief operations face uncertainty not only about the task, but also uncertainty related to the nature of the participants and the structure of the network itself. This is because of the complex dynamics of the organizations involved (Kalkman and de Waard, 2017). Uncertainty in supply is particularly relevant because the impact of a disaster can affect workforce availability (Santos et al, 2014). Koppenjan and Klijn (2004) introduce substantive, strategic, and institutional uncertainty as three main categories faced by organizations. The first is related to the situation itself, whereas the other two are related to the structure of the organizations involved. The perspective adopted by this article considers uncertainty in demand (i.e. victims) as well as the less studied uncertainty in supply (i.e. relief agencies). Such uncertainty can cause duplication of relief activities, shortages, or overcrowding which would impact the service provided to disaster victims.

The purpose of this article is then to present a novel two-stage stochastic programming 
model for disaster preparedness involving multiple governmental relief agencies. Differently from most papers in the current literature, we model the shortage risk due to the uncertain outcomes in terms of people deprived of assistance, which comprises of healthcare attention, relief aid, and shelter support. We build a function that represents the total number of people-at-risk as the weighted sum of those four terms, and reduce the corresponding shortage risk. This approach is accounting for the uncertainty in the supply of human and material resources, with the former being often overlooked in other formulations. Solutions balancing risk mitigation and logistics costs are devised for the resulting bi-objective model via the $\epsilon$ constraint method. A Geographical Information System (GIS) analysis is used to pre-process the model's inputs, such as the set of scenarios, and to generate comprehensive risk maps. Our approach is assessed based on scenarios stemming from real-life floods in the city of Veracruz, Mexico. In order to provide relevant managerial implications that can be further discussed with various Mexican authorities to improve the current disaster preparedness management in the country, we target two questions. First, how should a plan for disaster response for multiple governmental relief agencies guided by a central coordinator under uncertainty be prepared for the Mexican case? Second, what is the effect of incorporating uncertainty in supply, demand, and infrastructure in a plan for disaster response for multiple governmental relief agencies guided by a central coordinator?

The remaining article is structured as follows. Section 2 introduces a literature review of relevant studies and Section 3 describes the disaster preparedness problem. Section 4 introduces the two-stage scenario-based stochastic programming model, while Section 5 presents the application of the model to a real case in Veracruz, Mexico. Section 6 presents the discussion about the value of the stochastic approach, after which the conclusions and remaining challenges are mentioned in Section 7.

\section{BACKGROUND AND RELEVANT LITERATURE}

\subsection{Humanitarian logistics}

Optimization modelling has been one of the preferred methods to support decisionmaking in humanitarian logistics, especially looking at the combination of facility location, stock prepositioning, and relief distribution (Caunhye et al, 2012). Optimization models 
can incorporate challenges inherent to disaster management such as an uncertain number of victims, poor information, damaged infrastructure, and vulnerability to subsequent disasters (Alinaghian et al, 2019; $\mathrm{Hu}$ et al, 2017). Hence, there are several articles using stochastic optimization to address the topics studied in this article (Grass and Fischer, 2016; Hoyos et al, 2015). Two-stage stochastic models have shown significant potential to provide valuable solutions. Considering uncertain demand and unreliable network information, Döyen et al (2012) propose a multi-commodity model for the location of local and regional facilities, and it aims to minimize the total cost of the system including penalties for unmet demand. $\mathrm{Hu}$ et al (2015) propose a location-allocation model minimizing logistics cost and risk-induced penalties to determine rescues center selection and allocation of pumps in the first-stage, and distribution to affected areas in the second-stage. Ahmadi et al (2015) consider network failure to propose a two-stage stochastic program with random travel time to ascertain the location of distribution centers and routing for last-mile relief distribution. Alem et al (2016) consider fleet-sizing, procurement and budget allocation decisions to propose a two-stage formulation based on the minimization of cost and unmet demand. The model is focused on prepositioning and vehicle contracting in the first-stage, and relief distribution and inventory management in the second-stage. Pradhananga et al (2016) propose a static scenario-based three-echelon network model for relief distribution looking at uncertainty in demand, supply, the characteristics of the situation, and in the infrastructure. The model minimizes a non-linear function of social cost for supply facility selection. Noyan et al (2016) introduce a formulation determining location and capacity decisions in the first-stage, whilst resource allocation decisions are made in the second-stage. The objective of their model is to maximize expected accessibility. Ali Torabi et al (2018) propose a fuzzy-stochastic programming model to minimize cost, including penalty cost for unmet demand. First-stage decisions are focused on facility location and pre-positioning, whereas second-stage decisions provide the post-disaster procurement and distribution plan. Hu and Dong (2019) focus on facility location and the stock pre-positioning policy in the first-stage, and support decisions related to procurement, relief distribution and inventory management in the second stage. The model minimizes total expected cost including shortage penalties. Noyan and Kahvecioglu (2018) extend the work of Noyan et al (2016) by considering central and local distribution facili- 
ties to focus on last-mile distribution. The first-stage focuses on location decisions whereas the second-stage determines transportation decisions. The objective of their model is to minimize the expected value of an accessibility metric which the authors link to equity.

The discussion about the complexity of disaster operations (Holguín-Veras et al, 2013) has led to the development of more suitable objectives. Moreno et al (2018) propose to minimize logistic costs and deprivation costs in their formulation supporting facility location, transportation, and fleet-sizing. First-stage decisions are associated to procurement of vehicles and facility location, whereas the second stage determines inventory and relief distribution decisions. Paul and Zhang (2019) have developed a preparedness two-stage stochastic formulation for facility location, stock pre-positioning, and distribution. The first-stage of the model is focused on selecting the location of distribution points, medical stock levels, and transportation capacity. Second-stage variables are related to transportation decisions. The aim of their model is to minimize costs, considering deprivation costs in the formulation. However, even with the development of deprivation costs, Beamon Benita and Balcik (2008) argue that it is difficult to encapsulate the goals of humanitarian operations into a single objective. Thus, the complexity of humanitarian operations has encouraged authors to introduce multi-objective formulations to address these issues as well. Tofighi et al (2016) propose a formulation addressing location and pre-positioning decisions in the first stage, and a relief distribution plan in the second stage. The aim of the model is to minimize overall logistics costs in the first stage, and total distribution time, weighted travel time and cost, including shortage penalties for unmet demand, in the second stage. Manopiniwes and Irohara (2017) propose a multi-objective formulation minimizing cost and the maximum response time, the latter accounting for equity among the affected areas. First-stage decisions are focused on facility location and stock pre-positioning, whereas evacuation and relief distribution decisions are determined in the second-stage.

\subsection{Multiple stakeholders}

The articles presented so far have failed to consider the interaction between different organizations directly. The social networks created by these participants are essential to meet the needs of disaster victims because they involve the resources and activities performed in 
disaster operations (Holguín-Veras et al, 2012). Neglecting the presence of multiple participants can lead organizations to compete for scarce resources or deploy unnecessary resources in excess (Balcik et al, 2010; Auf der Heide and Irwin, 1989). Therefore, formulations designed to support humanitarian logistics need to include multiple organizations in the analysis (Rodríguez-Espíndola et al, 2018a). This becomes essential when uncertainty in supply is considered, because human resources are crucial to provide services in safe facilities.

\subsubsection{Game theory}

The discussion about the use of decentralized systems and the interaction of different stakeholders has led to an increase in articles on game theory within disaster management settings (Seaberg et al, 2017). Game theory considers different stakeholders with individual goals, which can aim to maximize their own objectives (non-cooperative games) or to create strategic alliances to maximize pay-offs (cooperative games)(Muggy and L. Heier Stamm, 2014). In the context of non-cooperative games, Adida et al (2011) aim to minimize stockpiling cost for medical equipment in collaborating hospitals. Nagurney et al (2016) have developed a General Nash Equilibrium model focusing on relief distribution. The model maximizes the utility of each player considering donations and cost-effectiveness. The authors have reformulated the problem as an optimization model and tested it under conditions based on the impact of hurricane Katrina. Toyasaki et al (2017) have developed a newsvendor model with the aim of minimizing cost for inventory management. Gossler et al (2019) explore the impact of transportation rates and framework agreements in transportation decisions. They use a sub-model looking at minimizing transportation cost and dependency risk of humanitarian organizations, and another sub-model looking at the behaviour of the carrier to maximize expected profit and customer satisfaction. The joint participation of distinct NGOs is addressed by Nagurney et al (2019) through an extension of Nagurney et al (2016). Their Generalized Nash equilibrium formulation determines the quantity of supplies to purchase, supplier selection, and relief distribution using a specific freight logistics provider. The authors use variational equilibrium and the Lagrange multiplier theory in the model and illustrate the behaviour of the model under conditions resembling the impact of Hurricane Harvey in the US. Muggy and Heier Stamm (2020) propose a centralized and 
a decentralized decision model to decide which facilities will be selected by beneficiaries in evacuations. Both network congestion games minimize utility comprised of travel distance and congestion in the facility, with the decentralized model looking at individual utility and the centralized model considering the overall travel distance and congestion in the system.

This stream of research can be interesting for the competition of resources (i.e. donations) between two players and to minimize demand congestion as presented in the literature (Seaberg et al, 2017). However, two common features were found in these articles. The preference for non cooperative games using monetary metrics captures the competition between organizations, but it does not account for agencies guided by an upper-level coordinator (except for the centralized model from Muggy and Heier Stamm (2020)). Additionally, in all cases the players and resources need to be known in advance and the use of the formulations can be complicated by the introduction of different sources of uncertainty.

\subsubsection{Resource allocation models}

Although there are valuable arguments supporting the development of decentralized systems (Quarantelli, 1988; Scolobig et al, 2015), in most countries there is an umbrella organization managing a subset of agencies with similar goals (Takeda Margaret and Helms Marilyn, 2006; Alexander, 2015; Gupta et al, 2016). Resource allocation models have proven useful to introduce human and material resources in the formulations with multiple participants. For instance, there are articles coordinating helicopter rescue tours minimizing cost (Barbarosoglu et al, 2002), the distribution of heavy equipment minimizing total travel time (Chen et al, 2011), the delivery of international resources minimizing cost (Adivar et al, 2010), the allocation of disaster refuge staff minimizing total weighted distance (Chou et al, 2014), and allocating teams of volunteers to tasks minimizing cost (Falasca and Zobel, 2012). Rodríguez-Espíndola et al (2018b) focus on facility location, stock prepositioning, and relief distribution. The deterministic model minimizes cost and maximizes level of service. The highlight of this formulation is the potential to optimize the number of stakeholders involved. However, the proposed formulation does not account for uncertainty in supply nor in demand, which can affect operations (Balcik et al, 2010). Velasquez et al (2019) use robust optimization to support stock prepositioning in disasters. Their article consid- 
ers multi-agency collaboration between governmental agencies and other organizations for procurement, allocation, and inventory. The objective of the model is to minimize the total demand-weighted distance from distribution centers to dispensing locations and the authors provide a greedy heuristic algorithm for solving the uncapacitated deterministic version of the model. Balcik et al (2019) introduce an insurance-based method to support facility location and stock prepositioning as part of horizontal collaboration. The model includes decisions about location, premiums and budgets in the first-stage, whereas the second-stage is focused on transportation and procurement. The aim is to minimize costs and deviation from the premium paid and the cost expected for the participants and it is solved using Cplex. Arif et al (2020) focus on the repair after disasters considering uncertainty in demand and repair times aiming to minimize cost. The first-stage of the model determines the facilities used and the initial allocation of crews and equipment, whilst second-stage decisions are focused on allocating crews to affected areas and ordering new equipment. Although the model considers the value of human resources, it does not account for congestion and uncertainty in supply. Introducing multiple objectives, Celik et al (2016) tackle the location-allocation problem in disaster response, minimizing cost. Their formulation manages location and pre-disaster procurement decisions in the first-stage, and post-disaster procurement and allocation in the second-stage. Sarma et al (2019) propose a model for resource allocation and facility location with resources pooled from NGOs and the government. Uncertainty is represented in the model using triangular neutrosophic numbers and the objectives of the formulation are to minimize cost and time. Their article provides a comparison of the neutrosophic compromise approach, the global criteria method, and the weighted sum method as solution methods with support from Lingo.

\subsection{Research gap}

The literature review presented previously shows the approaches undertaken to manage humanitarian logistics incorporating multiple participants. When uncertainty in supply, demand, and transportation is considered, two-stage formulations have shown significant value. Additionally, these models can account for the integration of different decisions and their interaction. However, most of these articles fail to consider the involvement of multiple 
organizations. Game formulations have shown remarkable potential to introduce different stakeholders with individual goals and to reduce congestion in demand. Nevertheless, in the context of an upper-level organization working as the coordinator, competition among agencies becomes less critical and the incorporation of several activities with the corresponding stochastic variables can become challenging. Although material congestion and demand congestion have been studied in these models, congestion from the perspective of human resources remains unexplored. Resource allocation models have potential to manage multiple decisions and account for uncertainty when including multiple participants working under a general coordinator. Nonetheless, the review of game theoretical articles and resource allocation models shows an absence of articles incorporating uncertainty and congestion in supply along with the delivery of both products and services. These formulations assume a set number of participants, rather than the variability encountered in real situations. Overall, these articles overlook congestion and stochastic supply. This is relevant because the provision of services in facilities is an understudied area and the convergence of human resources can create more challenges than solutions. Tables 1 and 2 show a comparison of the most relevant articles presented in the review with the proposed formulation. To address the challenges presented, in this paper we model the risk in terms of the number of people without humanitarian assistance, i.e., overall people at-risk, but we still need to ensure a minimum-cost solution to carry out the logistics activities as money is a critical resource in most disaster management contexts. Therefore, instead of merging these two goals in a single objective function aligned with the idea of social costs, we balance logistics costs and people at-risk in a bi-objective fashion to generate efficient (non-dominant) solutions that turn out to be effective from the decision-making point of view. Indeed, recent literature has pointed out that minimizing aid shortage and logistics costs separately might be appealing to avoid unnecessary relief aid rationing when resources are still available to meet victims' needs (Tofighi et al, 2016). Hence, this paper proposes a multi-objective two-stage stochastic formulation for facility location, stock prepositioning, relief distribution, and resource allocation considering uncertainty in supply, demand, and infrastructure capable of optimizing the number of agencies involved to reduce shortages and excess of human and material resources. 
Table 1: Problems addressed by the models reviewed

\begin{tabular}{|c|c|c|c|c|c|c|c|}
\hline Article & $\begin{array}{l}\text { Supply } \\
\text { facility } \\
\text { location }\end{array}$ & $\begin{array}{l}\text { Local } \\
\text { facility } \\
\text { location }\end{array}$ & $\begin{array}{l}\text { Relief } \\
\text { distri- } \\
\text { bution }\end{array}$ & $\begin{array}{l}\text { Stock } \\
\text { prepo- } \\
\text { sitioning }\end{array}$ & $\begin{array}{l}\text { Resource } \\
\text { allocation }\end{array}$ & Services & $\begin{array}{l}\text { Multi- } \\
\text { objective }\end{array}$ \\
\hline Döyen et al (2012) & $\checkmark$ & $\checkmark$ & & $\checkmark$ & $\checkmark$ & & \\
\hline Hu et al (2015) & $\checkmark$ & & & $\checkmark$ & $\checkmark$ & & \\
\hline Ahmadi et al (2015) & $\checkmark$ & & $\checkmark$ & & & & \\
\hline Alem et al (2016) & & & $\checkmark$ & $\checkmark$ & $\checkmark$ & & \\
\hline Pradhananga et al (2016) & $\checkmark$ & & & & $\checkmark$ & & \\
\hline Tofighi et al (2016) & $\checkmark$ & $\checkmark$ & $\checkmark$ & $\checkmark$ & $\checkmark$ & & $\checkmark$ \\
\hline Noyan et al (2016) & $\checkmark$ & & & & $\checkmark$ & & \\
\hline Çelik et al (2012) & $\checkmark$ & & & $\checkmark$ & $\checkmark$ & & \\
\hline Manopiniwes and Irohara (2017) & $\checkmark$ & & & $\checkmark$ & $\checkmark$ & & $\checkmark$ \\
\hline Noyan and Kahvecioglu (2018) & $\checkmark$ & $\checkmark$ & $\checkmark$ & & $\checkmark$ & & \\
\hline Ali Torabi et al (2018) & $\checkmark$ & $\checkmark$ & & $\checkmark$ & $\checkmark$ & & \\
\hline Moreno et al (2018) & $\checkmark$ & & $\checkmark$ & & $\checkmark$ & & $\checkmark$ \\
\hline Rodríguez-Espíndola et al (2018b) & $\checkmark$ & $\checkmark$ & $\checkmark$ & $\checkmark$ & $\checkmark$ & $\checkmark$ & $\checkmark$ \\
\hline Sarma et al (2019) & $\checkmark$ & & $\checkmark$ & & $\checkmark$ & & $\checkmark$ \\
\hline Paul and Zhang (2019) & $\checkmark$ & & $\checkmark$ & $\checkmark$ & $\checkmark$ & & \\
\hline Hu and Dong (2019) & $\checkmark$ & & $\checkmark$ & $\checkmark$ & $\checkmark$ & & \\
\hline Velasquez et al (2019) & $\checkmark$ & & & $\checkmark$ & $\checkmark$ & & \\
\hline Balcik et al (2019) & $\checkmark$ & & $\checkmark$ & $\checkmark$ & $\checkmark$ & & \\
\hline Arif et al (2020) & $\checkmark$ & & $\checkmark$ & $\checkmark$ & $\checkmark$ & & \\
\hline This article & $\checkmark$ & $\checkmark$ & $\checkmark$ & $\checkmark$ & $\checkmark$ & $\checkmark$ & $\checkmark$ \\
\hline
\end{tabular}

Table 2: Features of the models reviewed

\begin{tabular}{|c|c|c|c|c|c|c|c|}
\hline Article & $\begin{array}{l}\text { Multi- } \\
\text { product }\end{array}$ & $\begin{array}{l}\text { Multi- } \\
\text { modal }\end{array}$ & $\begin{array}{l}\text { Multi- } \\
\text { stakeholders }\end{array}$ & $\begin{array}{l}\text { Uncertain } \\
\text { demand }\end{array}$ & $\begin{array}{l}\text { Uncertain } \\
\text { supply }\end{array}$ & $\begin{array}{l}\text { Uncertain } \\
\text { infrastructure }\end{array}$ & $\begin{array}{l}\text { Human } \\
\text { Resources }\end{array}$ \\
\hline Döyen et al (2012) & $\checkmark$ & & & $\checkmark$ & & $\checkmark$ & \\
\hline Hu et al (2015) & & & & $\checkmark$ & & & \\
\hline Ahmadi et al (2015) & $\checkmark$ & $\checkmark$ & & & & $\checkmark$ & \\
\hline Alem et al (2016) & $\checkmark$ & $\checkmark$ & & $\checkmark$ & $\checkmark$ & $\checkmark$ & \\
\hline Pradhananga et al (2016) & $\checkmark$ & & & $\checkmark$ & $\checkmark$ & $\checkmark$ & \\
\hline Tofighi et al (2016) & $\checkmark$ & & & $\checkmark$ & $\checkmark$ & $\checkmark$ & \\
\hline Noyan et al (2016) & & & & $\checkmark$ & & $\checkmark$ & \\
\hline Çelik et al (2012) & $\checkmark$ & & $\checkmark$ & $\checkmark$ & & & \\
\hline Manopiniwes and Irohara (2017) & & $\checkmark$ & & $\checkmark$ & & $\checkmark$ & \\
\hline Noyan and Kahvecioglu (2018) & & & & $\checkmark$ & & $\checkmark$ & \\
\hline Ali Torabi et al (2018) & $\checkmark$ & & & $\checkmark$ & & $\checkmark$ & \\
\hline Moreno et al (2018) & $\checkmark$ & $\checkmark$ & & $\checkmark$ & $\checkmark$ & $\checkmark$ & \\
\hline Rodríguez-Espíndola et al (2018b) & $\checkmark$ & $\checkmark$ & $\checkmark$ & & & & $\checkmark$ \\
\hline Sarma et al (2019) & $\checkmark$ & & & & & $\checkmark$ & \\
\hline Paul and Zhang (2019) & & & & $\checkmark$ & $\checkmark$ & $\checkmark$ & \\
\hline Hu and Dong (2019) & & & & $\checkmark$ & $\checkmark$ & & \\
\hline Velasquez et al (2019) & $\checkmark$ & & $0^{\checkmark}$ & $\checkmark$ & & & \\
\hline Balcik et al (2019) & & $\checkmark$ & ${ }^{9}$ & $\checkmark$ & $\checkmark$ & $\checkmark$ & \\
\hline Arif et al (2020) & $\checkmark$ & & & $\checkmark$ & & $\checkmark$ & $\checkmark$ \\
\hline This article & $\checkmark$ & $\checkmark$ & $\checkmark$ & $\checkmark$ & $\checkmark$ & $\checkmark$ & $\checkmark$ \\
\hline
\end{tabular}




\section{PROBLEM STATEMENT AND MATHEMATICAL MODEL}

The formulation to be proposed in this paper considers a centralized decision-making structure, as the one used by several governments globally (Takeda and Helms, 2006). In this system, a coordinating body functions as an umbrella to orchestrate the operations of different agencies (Takeda and Helms, 2006). Resources of the different participants are at the disposal of this coordinating body and it controls the flow of information to manage them.

\subsection{Preparedness management: The Mexican context}

In Mexico, the disaster management structure has been developed around the Civil Protection National Council (SINAPROC), which is supported by three different branches, as shown in Figure 1. The Ministry of Interior is the entity responsible for managing the executive coordination in cases of disaster, involved with agencies on the three government levels, i.e. National, State and Municipal. Technical coordination refers to agencies with the capability to provide technical advice for disaster management, whereas co-responsibility refers to agencies providing supplementary support along with human and material resources to emergency activities on top of their normal duties (SEGOB, 2006).

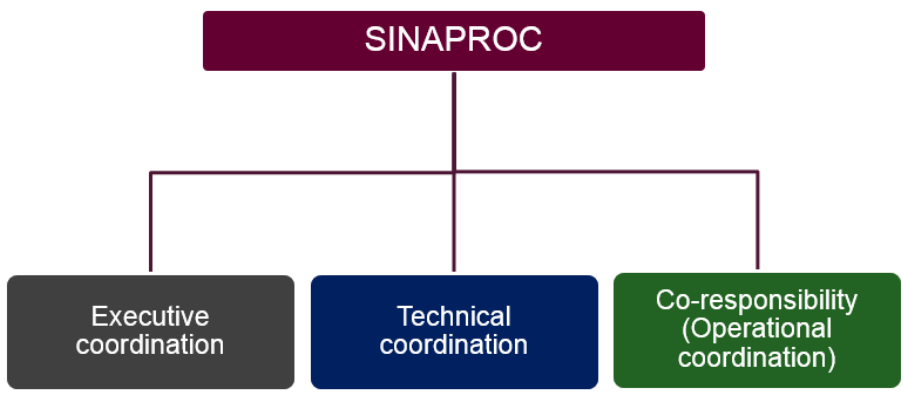

Figure 1: Mexican disaster management structure. Source: SEGOB (2006).

Before a potential disaster occurs (e.g. rain season, or the approach of a hurricane), a set of agencies identify potentially safe facilities to operate as shelters and distribution centers. Items are prepositioned in prospective distribution centers or warehouses as this strategy is deemed as the most efficient in the literature (Rezaei-Malek et al, 2016; Hu et al, 2017), whilst shelters are prepared for the arrival of displaced people. After the disaster strikes, 
the response plan is agreed upon by all the agencies with the coordinating body. Relief aid along with vehicles and people are sent to the disaster area based on information about the characteristics of the disaster.

Figure 2 shows the Mexican disaster response process at every stage. If the capacity of the agencies available at the current level is insufficient to meet demand, the disaster is escalated to the next level up to involve more agencies. Although this procedure is controlling the number of participants depending on the level (i.e. local, regional, national or international), at each stage several agencies are activated simultaneously, which in many cases results in idle participants.

Considering the potential number of stakeholders, there is a need for decision support systems to organize and optimize their activities to reduce the risk of people without products and services. The formulation proposed deals with the management of human and material resources under uncertain conditions. Shortages are commonly considered by decisionmakers, but the risk of oversupply is often overlooked. This research is tackling the challenge of convergence through the optimization of the number of agencies involved in logistics activities, which ensures that only the required human and material resources are deployed.

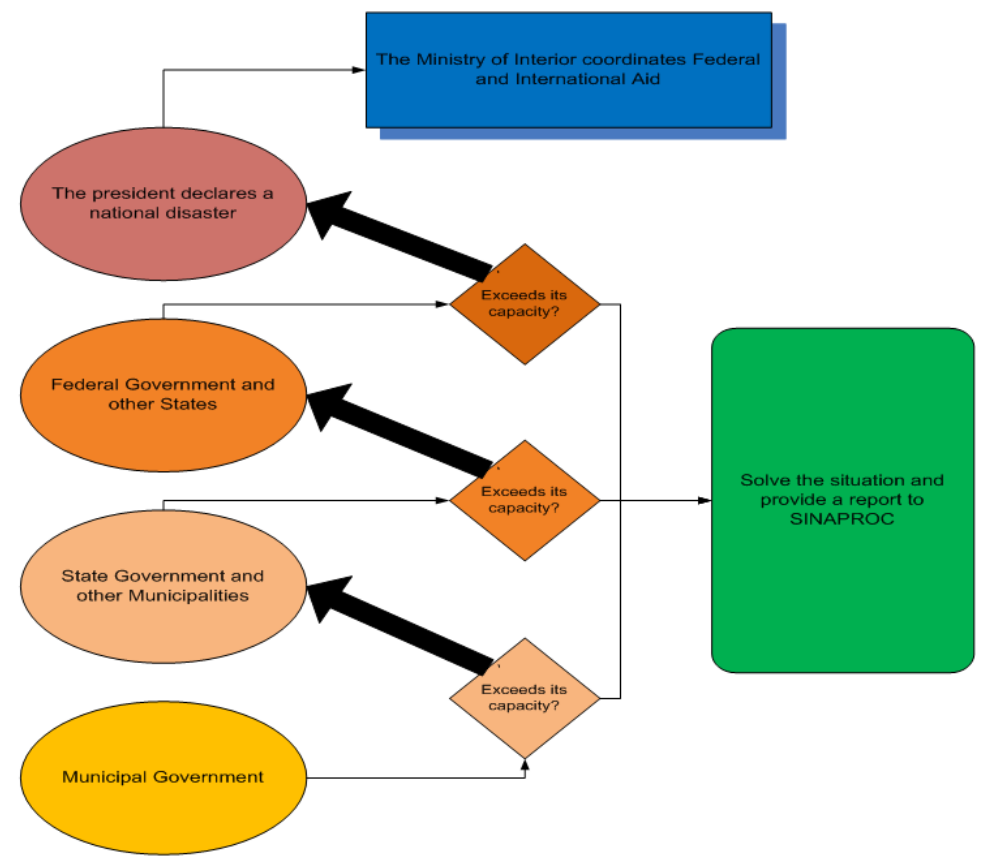

Figure 2: Disaster management process in Mexico. Source: SEGOB (2006) 


\subsection{The role of the two-stage modelling in disaster preparedness}

In disaster management it is common to select a number of possible occurrences for uncertain parameters, thus assuming that the disaster will behave according to those. By incorporating all these occurrences into an optimization model, it is possible to determine robust implementable decisions, which are supposedly "good" strategies to hedge against any materialized outcome, and at the same time, a set of flexible contingency decisions relative to each outcome. This situation describes a typical two-stage stochastic programming approach in which uncertainties are modelled as random variables in a given probability space composed of a set $\mathcal{S}$ of realizations of the random variables, or the so-called scenarios, such that $\pi_{s}$ refers to the probability of occurrence of scenario $s \in S$, such that $\sum_{s \in \mathcal{S}} \pi_{s}=1$ and $\pi_{s}>0$ hold for all $s \in \mathcal{S}$. In the two-stage framework, variables are divided in either first- or second-stage decisions. In this research, the Mexican disaster management framework was employed to identify the stage of each variable according to the sequence of events in real life, namely preparedness and response, as suggested in previous literature (Manopiniwes and Irohara, 2017).

First-stage decisions are taken without knowing the precise value of the random variables, but regardless of the impact or the characteristics of the flood disaster, first-stage decisions must be feasible and "ready to be implementable". In our context, that means decisions have to be made before disaster strikes. A time horizon of at least two weeks before the disaster strikes is suggested because each activity can be very time-consuming due to the inherent bureaucracy. Co-responsibility agencies identify and disseminate facilities to be used for distribution and for sheltering people. The number of people to be expected at each facility provides information about the number and location of required shelters, whereas the quantity and location of prepositioned relief is linked to the number and location of opened distribution centers. These variables inform SINAPROC about the number and allocation of employees and vehicles required, which can support the decision about the agencies required in the field. As a result, these variables were labelled as first-stage variables. In this fashion, resources are prepared and ready to be deployed after the disaster strikes.

During the response, it is possible to remedy the decisions made in the first-stage via the second-stage decisions for each possible scenario. Second stage decisions are expected to 
support the immediate response after the disaster strikes for one period of time, allowing the ongoing response plan to be drafted. In the Mexican case, that represents a time horizon of four days. The objective function must account for the expected cost composed by the first-stage and the second-stage costs, as part of SINAPROC's budget. Figure 3 shows a scheme of the proposed two-stage approach to the disaster preparedness planning proposed in this paper.

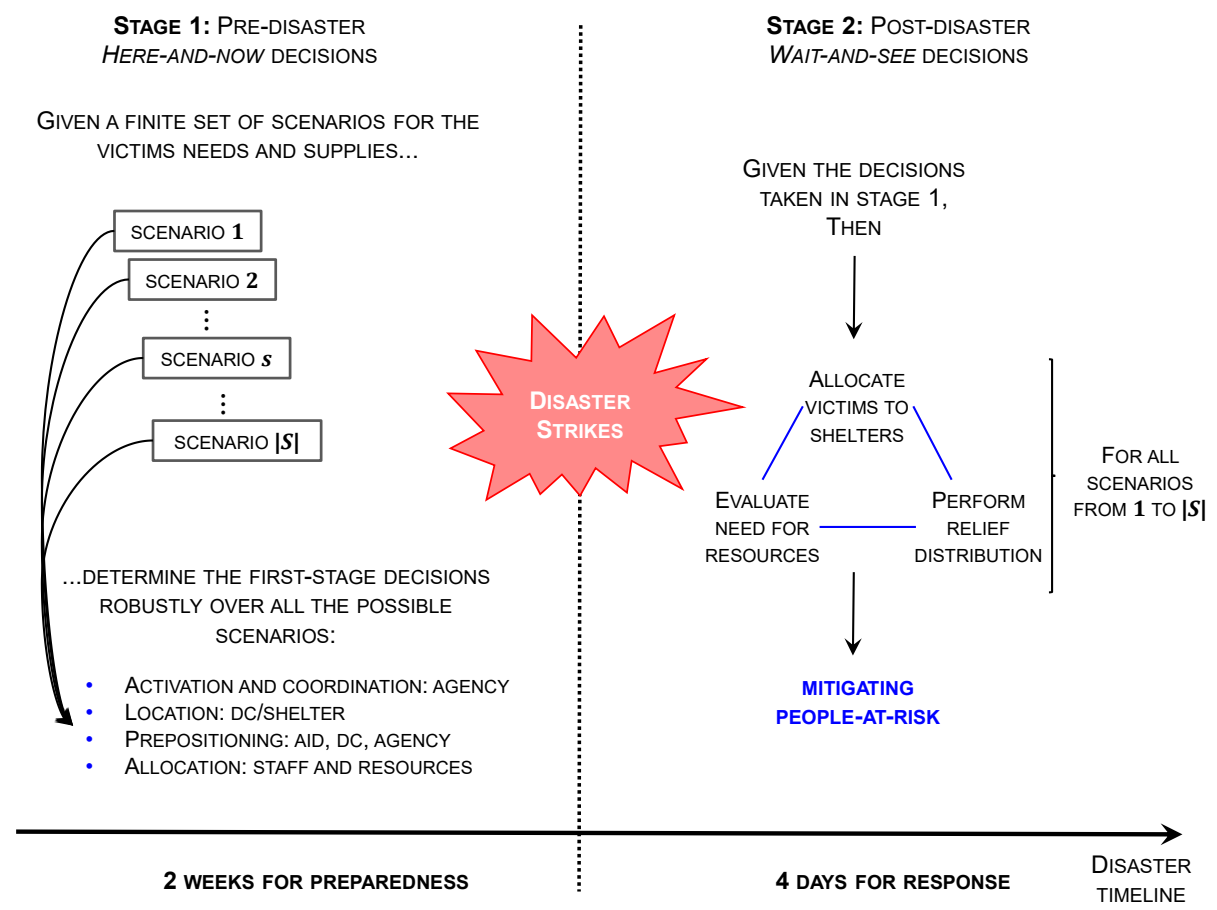

Figure 3: Scheme of the two-stage paradigm applied to the disaster preparedness proposed in this paper.

Relief distribution is classified as a second-stage activity. After the disaster strikes, the co-responsibility branch delivers products from the distribution centers to the shelters. Therefore, in the second stage the demand for products and services is obtained, and the model provides SINAPROC with information about quantity of resources to deploy and shipment mode. Also, potential shortages and surplus of people and products are determined, which affect the fill rate. Thus, the variables related to these activities were classified as second-stage variables as well. 


\subsection{A preparedness two-stage stochastic model for multi-agency coordination}

In order to state the mathematical model, we will define the main entities of our problem in terms of the following sets: $\mathcal{I}$ for the candidate distribution centers (DCs); $\mathcal{J}$ for the candidate shelters; $\mathcal{K}$ for the demand areas; $\mathcal{M}$ for the transportation modes; $\mathcal{N}$ for the products; $\mathcal{O}$ for the agencies; and $\mathcal{S}$ for the scenarios. The input parameters and the decisions supported by the optimization model are described in Tables 3, 4, 5, and 6 .

Table 3: Deterministic Parameters.

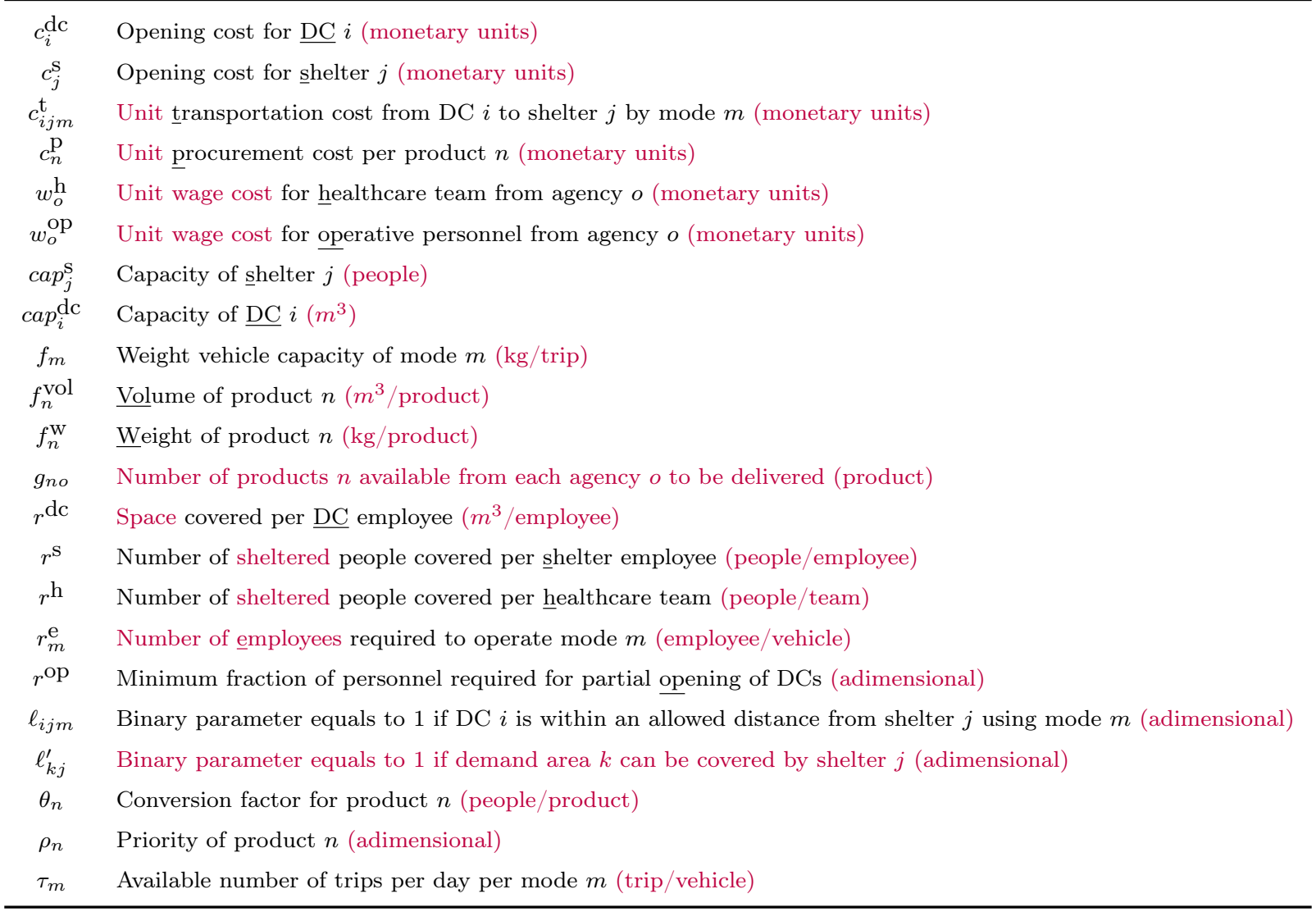


Table 4: Stochastic Parameters.

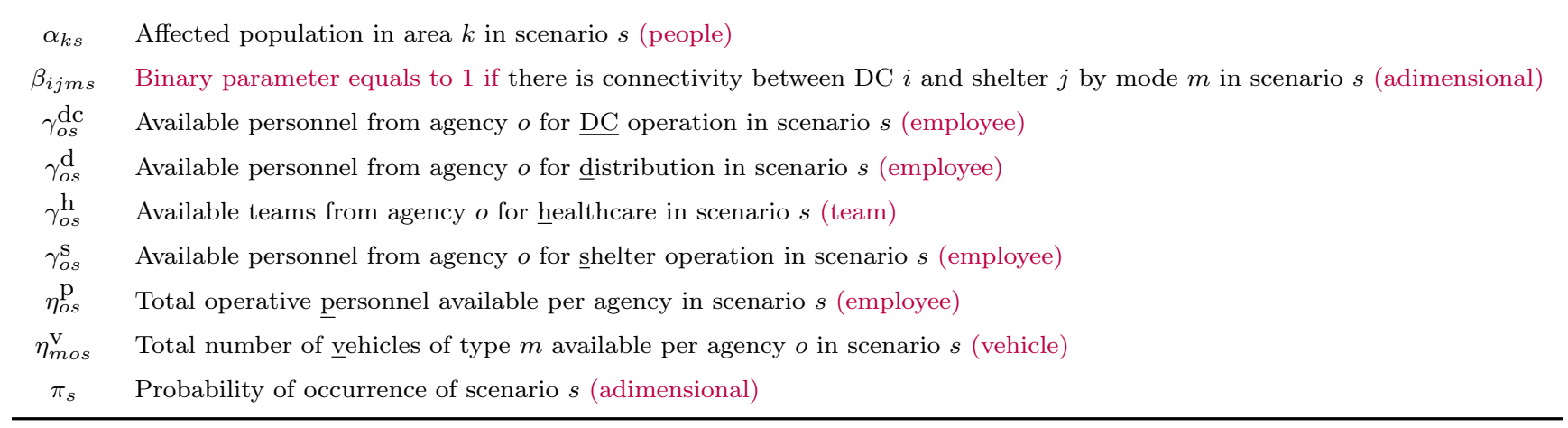

Table 5: First-stage Decision Variables.

$\begin{array}{cl}P_{n i o} & \text { Quantity of stock of product } n \text { to preposition at DC } i \text { by agency } o \text { (product) } \\ Q_{o i}^{\mathrm{dc}} & \text { Number of staff from agency o to be allocated to } \underline{\mathrm{DC}} i \text { (employee) } \\ Q_{o i m}^{\mathrm{d}} & \text { Number of staff from agency o to be allocated to distribution associated with mode } m \text { in DC } i \text { (employee) } \\ Q_{o j}^{\mathrm{h}} & \text { Number of teams from agency } o \text { to be allocated to healthcare activities in shelter } j \text { (team) } \\ Q_{o j}^{\mathrm{s}} & \text { Number of staff from agency o to be allocated to shelter } j \text { (employee) } \\ V_{i m o} & \text { Number of vehicles to be allocated to each DC (vehicle) } \\ W_{o} & \text { Whether to activate an agency } o\left(W_{o}=1\right) \text { or not }\left(W_{o}=0\right) \\ X_{i} & \text { Whether to open a DC at location } i\left(X_{i}=1\right) \text { or not }\left(X_{i}=0\right) \\ Y_{j} & \text { Whether to open a shelter at location } j\left(Y_{j}=1\right) \text { or not }\left(Y_{j}=0\right)\end{array}$

Table 6: Second-stage Decision Variables.

\begin{tabular}{cl}
\hline$D_{j s}$ & Number of people to be allocated to each shelter $j$ and scenario $s$ (people) \\
$D_{k j s}^{\prime}$ & People to be allocated from each demand zone $k$ to shelter $j$ in scenario $s$ (people) \\
$D_{j n s}^{\prime \prime}$ & Number of products $n$ required at shelter $j$ in scenario $s$ (product) \\
$U_{k s}^{\mathrm{s}}$ & Number of people from demand area $k$ without shelter in scenario $s$ (people) \\
$U_{j s}^{\mathrm{h}}$ & Number of people without healthcare in shelter $j$ in scenario $s$ (people) \\
$U_{j s}^{\mathrm{a}}$ & Number of people without attention in shelter $j$ in scenario $s$ (people) \\
$U_{j s}^{\mathrm{r}}$ & Weighted number of people without relief aid in shelter $j$ in scenario $s$ (people) \\
$U_{j n s}^{\prime}$ & Relief aid shortage of product $n$ in shelter $j$ in scenario $s$ (product) \\
$Z_{i j m n s}$ & Flow of products $n$ from DC $i$ to shelter $j$ by mode $m$ in scenario $s$ (product) \\
$Z_{i j m s}^{\prime}$ & Number of trips from DC $i$ to shelter $j$ by mode $m$ in scenario $s$ (trip) \\
\hline
\end{tabular}


The two-stage stochastic programming model for multi-agency coordination in pre-disaster logistics planning towards mitigating the shortage risk within a given financial budget is modelled as follows:

$$
\text { Min }\langle\text { Risk, COST〉, }
$$

in which

$$
\operatorname{RISK}=\sum_{s \in \mathcal{S}} \pi_{s} \cdot\left[\frac{\sum_{j \in \mathcal{J}}\left(U_{j s}^{\mathrm{a}}+U_{j s}^{\mathrm{h}}+U_{j s}^{\mathrm{r}}\right)}{3}+\sum_{k \in \mathcal{K}} U_{k s}^{\mathrm{s}}\right]
$$

and

$$
\begin{aligned}
\operatorname{CosT}= & \sum_{i \in \mathcal{I}} c_{i}^{\mathrm{dc}} \cdot X_{i}+\sum_{j \in \mathcal{J}} c_{j}^{\mathrm{s}} \cdot Y_{j}+\sum_{i \in \mathcal{I}} \sum_{n \in \mathcal{N}} \sum_{o \in \mathcal{O}} c_{n}^{\mathrm{p}} \cdot P_{n i o}+ \\
& +\sum_{s \in \mathcal{S}} \pi_{s} \cdot\left[\sum_{o \in \mathcal{O}}\left(w_{o}^{\mathrm{h}} \cdot \gamma_{o s}^{\mathrm{h}}+w_{o}^{\mathrm{op}} \cdot \eta_{o s}^{\mathrm{p}}\right) \cdot W_{o}+\sum_{i \in \mathcal{I}} \sum_{j \in \mathcal{J}} \sum_{m \in \mathcal{M}} c_{i j m}^{\mathrm{t}} \cdot Z_{i j m s}^{\prime}\right] .
\end{aligned}
$$

The use of multiple criteria is useful for decision-making in complex situations (Zhang et al, 2019). This research incorporates two objective functions to balance the use of resources and the level of service.

The first objective function (2), called RISK, represents the overall number of victims without any type of assistance, comprising of relief aid (first term), healthcare (second term), security and care (third term), and shelter provision (fourth term), which are usually offered by Mexican authorities (Rodríguez-Espíndola et al, 2018b). Notice that the first part of objective (2) is divided by three because the three terms represent the needs for sheltered people, whereas the last term involves the provision of shelter. The function in the most basic case suggests providing shelter to affected victims if possible. Once that has been fulfilled, the formulation encourages the provision of as much support as possible among the three initial terms depending on the constraints. The objective function (2) can account for the people at risk of not having shelter, or the people allocated to a shelter but at risk of not having the products/services required. This function encapsulates the balance between location and distribution decisions addressed by the paper. People at risk of not having shelter would automatically not have the products/services provided at shelters. Therefore, by minimizing expression (2), we attempt to mitigate the so-called shortage risk. The objective function is novel because most articles are focusing on relief shortage, leaving aside service provision in 
shelters. These services, such as healthcare, are essential to provide support for victims $(\mathrm{Gu}$ et al, 2018).

The second objective (3), called COST, aims at minimizing the logistics expenditures necessary to conduct both pre- and post-disaster operations. The first three terms involve the first-stage costs due to the location of distribution centers, location of shelters, and procurement of products, respectively. The last three terms together represent the expected second-stage costs incurred by personnel allocation and transportation decisions. Here, transportation costs are considered constant across scenarios. Disruptions in the network after a disaster strikes are captured using $\beta_{i j m s}$, which prevents activating an unavailable path as expressed by constraint (22). This simplifies the transportation network considerably. Next we present the constraints for our two-stage stochastic programming model.

The set of equations (4) determines the number of people allocated to shelters and the potential number of people without refuge. It is worth noting that $\ell_{k j}^{\prime}$ allows the decisionmaker to allocate people evacuating from their homes to facilities closer than a maximum coverage distance. This can be obtained from the combination of a distance matrix and the maximum travel distance specified by the decision-maker. The final matrix is obtained assigning a value of 1 to links below the maximum threshold and a value of 0 for longer distances to prevent people from being allocated far from their living area. Equation (5) determines the number of people to be served at each shelter and constraint (6) ensures shelter capacity is not exceeded. Expression (7) determines the demand of products per shelter based on demand. This constraint converts the potential number of victims to the number of kits required based on the number of people served per kit.

$$
\begin{aligned}
\alpha_{k s} & =\sum_{j \in \mathcal{J}} \ell_{k j}^{\prime} \cdot D_{k j s}^{\prime}+U_{k s}^{\mathrm{s}}, \forall k \in \mathcal{K}, s \in \mathcal{S} \\
D_{j s} & =\sum_{k \in \mathcal{K}} D_{k j s}^{\prime}, \forall j \in \mathcal{J}, s \in \mathcal{S} \\
D_{j s} \leq & c a p_{j}^{\mathrm{s}} \cdot Y_{j}, \forall j \in \mathcal{J}, s \in \mathcal{S} \\
D_{j n s}^{\prime \prime} \geq & \frac{D_{j s}}{\theta_{n}}, \forall j \in \mathcal{J}, n \in \mathcal{N}, s \in \mathcal{S}: \theta_{n}>0, \forall n \in \mathcal{N} .
\end{aligned}
$$

Example 1. Suppose that there are two candidate shelters, $j=1,2$, and one demand area, 
$k=1$. Let us assume four cases for $\ell_{k j}^{\prime}$ : (i) Both shelters can cover the demand area, i.e., $\ell_{11}^{\prime}=\ell_{12}^{\prime}=1$; (ii) Only shelter 1 can cover the demand area, i.e., $\ell_{11}^{\prime}=1, \ell_{12}^{\prime}=0$; (iii) Only shelter 2 can cover the demand area, i.e., $\ell_{11}^{\prime}=0, \ell_{12}^{\prime}=1$; (iv) No shelter can cover the affected area, i.e., $\ell_{11}^{\prime}=\ell_{12}^{\prime}=0$. For all the scenario-dependent constraints, $s \in \mathcal{S}$ holds true. The resulting constraints (4) are thus written as follows: (i) $\alpha_{1 s}=D_{11 s}^{\prime}+D_{12 s}^{\prime}+U_{1 s}^{\text {ss }}$; (ii) $\alpha_{1 s}=D_{11 s}^{\prime}+U_{1 s}^{\text {ss }}$; (iii) $\alpha_{1 s}=D_{12 s}^{\prime}+U_{1 s}^{\text {ss }}$; (iv) $\alpha_{1 s}=U_{1 s}^{\text {ss }}$. In the first case, we say that the affected population $\alpha_{k s}$ can be allocated to either shelter 1 or 2 ; the model will decide on the best combination between the decision variables $D_{11 s}^{\prime}$ and $D_{12 s}^{\prime}$. In the fourth case, because no shelter covers the given demand area, then its affected population $\alpha_{k s}$ cannot be allocated to them, implying that the decision variables associated with the allocation are both zero, $D_{11 s}^{\prime}=0$ and $D_{12 s}^{\prime}=0$. Cases 2 and 3 are straightforward. Focusing on case 1, the overall number of people to be allocated to shelters 1 and 2 is simply given by constraint (5): $D_{1 s}=D_{11 s}^{\prime}$ and $D_{2 s}=D_{12 s}^{\prime}$, such that the shelter capacities given by constraints (6) are not violated, i.e., $D_{1 s} \leq c a p_{1}^{\mathrm{s}} \cdot Y_{1}$ and $D_{2 s} \leq c a p_{2}^{\mathrm{s}} \cdot Y_{2}$, respectively. Now, assume we only have food products to deliver, $n=1$. The conversion factor, e.g. $\theta_{1}=4$, means that one unit of this product serves 4 people. Therefore, constraint (7) shows that the quantity of food products that should be in each shelter is simply the number of people allocated to this shelter over 4 , i.e., $D_{11 s}^{\prime \prime} \geq \frac{D_{1 s}}{4}$ and $D_{21 s}^{\prime \prime} \geq \frac{D_{2 s}}{4}$. If $D_{1 s}=1000$ and $D_{2 s}=400$, we should guarantee that there will be $D_{11 s}^{\prime \prime}=250$ food products in shelter 1 and $D_{21 s}^{\prime \prime}=100$ food products in shelter 2 .

For distribution centers, constraint (8) determines the personnel required for their operation, and constraint (9) ensures storage capacity of these facilities is not exceeded.

$$
\begin{aligned}
r^{\mathrm{dc}} \cdot \sum_{o \in \mathcal{O}} Q_{o i}^{d c} \geq r^{\mathrm{op}} \cdot c a p_{i}^{\mathrm{dc}} \cdot X_{i}, \forall i \in \mathcal{I} \\
\sum_{n \in \mathcal{N}} f_{n}^{\mathrm{vol}} \cdot \sum_{o \in \mathcal{O}} P_{n i o} \leq c a p_{i}^{\mathrm{dc}} \cdot X_{i}, \forall i \in \mathcal{I}
\end{aligned}
$$

Example 2. Assume that there is one distribution center, $i=1$, one food product, $n=1$, and two agencies, $o=1,2$. In addition, $r^{\text {op }}=1$, meaning that we need to have $100 \%$ of the required personnel to open any distribution center, $\operatorname{cap}_{1}^{\mathrm{dc}}=3000\left(\mathrm{~m}^{3}\right), r^{\mathrm{dc}}=60$ 
( $\mathrm{m}^{3}$ /employee), which means that one employee can manage $60 \mathrm{~m}^{3}$ of any distribution center. Then, by constraint (8), we have $60 \cdot\left(Q_{11}^{d c}+Q_{21}^{d c}\right) \geq 1 \cdot 3000 \cdot X_{1}$, implying $Q_{11}^{d c}+Q_{21}^{d c} \geq$ $50 \cdot X_{1}$. If $X_{1}=1$, this constraint indicates we need at least 50 employees in distribution center 1 ; these employees can come from either organization 1 or 2 . $r^{\mathrm{op}}=0.9$ indicates we can open any distribution center with 10\% less personnel, which means we would need at least 45 employees in distribution center 1 . Based on the same example, let $f_{1}^{\mathrm{vol}}=0.024$ $\left(\mathrm{m}^{3} /\right.$ product) be the volume of one unit of food product. Then, by constraint (9), we have $0.024 \cdot\left(P_{111}+P_{112}\right) \leq 3000 \cdot X_{1} \rightarrow P_{111}+P_{112} \leq \frac{3000}{0.024} \cdot X_{1}$. Therefore, $X_{1}=1$ implies that the total quantity of food products prepositioned in distribution center 1 by either agency 1

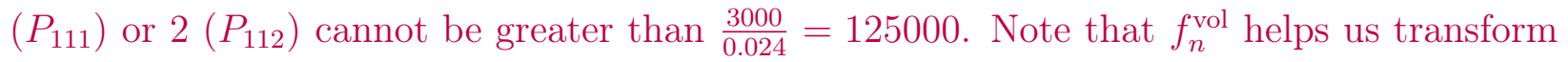
storage capacity from $\mathrm{m}^{3}$ to units of products.

Expression (10) restricts the availability of procured items for prepositioning and constraint (11) ensures that the number of items shipped is less than or equal to the number of products prepositioned.

$$
\begin{gathered}
\sum_{i \in \mathcal{I}} P_{\text {nio }} \leq g_{\text {no }} \cdot W_{o}, \forall n \in \mathcal{N}, o \in \mathcal{O} \\
\sum_{j \in \mathcal{J}} \sum_{m \in \mathcal{M}} Z_{\text {ijmns }} \leq \sum_{o \in \mathcal{O}} P_{\text {nio }}, \forall i \in \mathcal{I}, n \in \mathcal{N}, s \in \mathcal{S}
\end{gathered}
$$

The set of constraints (12) evaluates the relief aid shortage for each product, shelter, and scenario, as the difference between the number of products required by a given shelter and the total number of products that were sent to it. Constraint (13) finds the corresponding weighted number of people without relief aid at each shelter and scenario considering the priority of the products. Constraints (14) and (15) define the allocation of staff for healthcare and shelter attention, respectively. It is important to define the healthcare team. A healthcare team is integrated by a medical professional and one member of operative staff for support according to regulations (PCV, 2014). This team can provide healthcare coverage to a set number of victims according to governmental guidelines and it is represented by $r^{\mathrm{h}}$. 


$$
\begin{aligned}
U_{j n s}^{\prime} & =D_{j n s}^{\prime \prime}-\sum_{i \in \mathcal{I}} \sum_{m \in \mathcal{M}} Z_{i j m n s}, \forall j \in \mathcal{J}, n \in \mathcal{N}, s \in \mathcal{S} \\
U_{j s}^{\mathrm{r}} & \geq \frac{\sum_{n \in \mathcal{N}} \theta_{n} \cdot \rho_{n} \cdot U_{j n s}^{\prime}}{\sum_{n \in \mathcal{N}} \rho_{n}}, \forall j \in \mathcal{J}, s \in \mathcal{S} \\
D_{j s} & \geq r^{\mathrm{h}} \cdot \sum_{o \in \mathcal{O}} Q_{o j}^{\mathrm{h}}+U_{j s}^{\mathrm{h}}, \forall j \in \mathcal{J}, s \in \mathcal{S} \\
D_{j s} & \geq r^{\mathrm{s}} \cdot \sum_{o \in \mathcal{O}} Q_{o j}^{\mathrm{s}}+U_{j s}^{\mathrm{a}}, \forall j \in \mathcal{J}, s \in \mathcal{S} .
\end{aligned}
$$

Example 3. Suppose we have one candidate shelter, $j=1$, one distribution center, $i=1$, two products, $n=1,2$, one transportation mode, $m=1$, and two agencies $o=1,2$. For all the scenario-dependent constraints, $s \in \mathcal{S}$ holds true. Thus, constraint (12) gives $U_{11 s}^{\prime}=$ $D_{11 s}^{\prime \prime}-Z_{1111 s}$ and $U_{12 s}^{\prime}=D_{12 s}^{\prime \prime}-Z_{1112 s}$, showing that the relief aid shortage for product 1 (resp. product 2) in shelter 1 is the difference between the number of products required by this shelter and the total number of products shipped from distribution center 1 through mode 1 to shelter 1 . Both products are required by each victim. Assume now we have the conversion factors $\theta_{1}=4$ for product 1 and $\theta_{2}=100$ for product 2 , meaning that product 1 serves four people and product 2 serves 100 people. By setting equal priorities $\rho_{1}=1$ and $\rho_{2}=1$, constraint (13) gives $U_{1 s}^{\mathrm{r}} \geq \frac{\theta_{1} \cdot \rho_{1} \cdot U_{1 s}^{\prime}+\theta_{2} \cdot \rho_{2} \cdot U_{12 s}^{\prime}}{\rho_{1}+\rho_{2}}=2 \cdot U_{11 s}^{\prime}+50 \cdot U_{12 s}^{\prime}$. This is the weighted number of people with shortages. Hence, shortage of one unit of product two affects 25 times more people than shortage of one unit of product one after taking conversion and priority into account. If $U_{11 s}^{\prime}=25$ and $U_{12 s}^{\prime}=1, U_{1 s}^{\mathrm{r}}$ would be 100 , which means a shortage of products for 100 people (as priorities are equal). That value is optimized in the objective function, favouring the delivery of more critical items which can cover more people. The reason for using 'greater than' rather than 'equal to' in the constraint is because $U_{1 s}^{\mathrm{r}}$ is an integer variable and the constraint can potentially return fractional values.

Expressions (16), (17), (18) and (19) establish the maximum number of personnel available per agency for the operation of distribution centers, relief distribution activities associated with each transportation mode, healthcare provision, and shelter care service, respectively. 


$$
\begin{array}{r}
\sum_{i \in \mathcal{I}} Q_{o i}^{\mathrm{dc}} \leq \gamma_{o s}^{\mathrm{dc}} \cdot W_{o}, \forall o \in \mathcal{O}, s \in \mathcal{S} \\
\sum_{i \in \mathcal{I}} \sum_{m \in \mathcal{M}} Q_{o i m}^{\mathrm{d}} \leq \gamma_{o s}^{\mathrm{d}} \cdot W_{o}, \forall o \in \mathcal{O}, s \in \mathcal{S} \\
\sum_{j \in \mathcal{J}} Q_{o j}^{\mathrm{h}} \leq \gamma_{o s}^{\mathrm{h}} \cdot W_{o}, \forall o \in \mathcal{O}, s \in \mathcal{S} \\
\sum_{j \in \mathcal{J}} Q_{o j}^{\mathrm{s}} \leq \gamma_{o s}^{\mathrm{s}} \cdot W_{o}, \forall o \in \mathcal{O}, s \in \mathcal{S} .
\end{array}
$$

Constraint (20) ensures that the total number of staff from each agency activated falls within the total operative personnel available per agency in each scenario, including the term for healthcare teams if and only if the operative member of the team is available for operative support.

$$
\sum_{i \in \mathcal{I}} Q_{o i}^{\mathrm{dc}}+\sum_{i \in \mathcal{I}} \sum_{m \in \mathcal{M}} Q_{o i m}^{\mathrm{d}}+\sum_{j \in \mathcal{J}} Q_{o j}^{\mathrm{h}}+\sum_{j \in \mathcal{J}} Q_{o j}^{\mathrm{s}} \leq \eta_{o s}^{\mathrm{p}} \cdot W_{o}, \forall o \in \mathcal{O}, s \in S
$$

Constraint (21) determines the required staff for relief distribution based on the number of trips between facilities determined in constraint (22). Notice that if either $\ell_{i j m}=0$ or $\beta_{i j m s}=0$, then there is no flow of products between distribution center $i$ and shelter $j$ using mode $m$ in scenario $s$ and, consequently, the number of trips is also zero. Constraint (23) establishes the number of vehicles required for the trips. Notice that $\tau_{m}$ is a parameter based on the preferences of the decision-maker and agreements with the agencies involved in the distribution activities. Eventually, if the number of trips is not an issue for the agencies in charge of the distribution activities, $\tau_{m}$ can be set to a sufficiently large number. Expression (24) ensures the number of vehicles used does not exceed the number of vehicles available.

$$
\begin{gathered}
V_{i m o} \leq \frac{Q_{o i m}^{\mathrm{d}}}{r_{m}^{\mathrm{e}}}, \forall i \in \mathcal{I}, m \in \mathcal{M}, o \in \mathcal{O} \\
\sum_{n \in \mathcal{N}} f_{n}^{\mathrm{w}} \cdot Z_{i j m n s} \leq f_{m} \cdot \ell_{i j m} \cdot \beta_{i j m s} \cdot Z_{i j m s}^{\prime}, \forall i \in \mathcal{I}, j \in \mathcal{J}, m \in \mathcal{M}, s \in \mathcal{S} \\
\sum_{j \in \mathcal{J}} Z_{i j m s}^{\prime} \leq \tau_{m} \cdot \sum_{o \in \mathcal{O}} V_{i m o}, \forall i \in \mathcal{I}, m \in \mathcal{M}, s \in \mathcal{S} \\
\sum_{i \in \mathcal{I}} V_{i m o} \leq \eta_{m o s}^{\mathrm{v}} \cdot W_{o}, \forall m \in \mathcal{M}, o \in \mathcal{O}, s \in \mathcal{S} .
\end{gathered}
$$


Example 4. Suppose we have one distribution center, $i=1$, one shelter, $j=1$, one mode, $m=1$, one agency, $o=1$, and two products, $n=1,2$. In addition, let $r_{1}^{\mathrm{e}}=5$ be the number of employees needed to operate mode 1 . Thus, constraint $(21)$ shows us that $V_{111} \leq \frac{Q_{111}^{\mathrm{d}}}{5}$. Assuming that the number of personnel from agency 1 allocated to distribution center 1 to operate mode 1 is $Q_{111}^{\mathrm{d}}=1000$, then $V_{111} \leq \frac{1000}{5}=200$, showing that distribution center 1 cannot have more than 200 vehicles (mode 1 ) allocated by agency 1 . Let $f_{1}^{\mathrm{w}}=7.5$ and $f_{2}^{\mathrm{w}}=$ 18.2 be the weights (kg/product) of product 1 (food) and product 2 (medicine). In addition, let $f_{1}=2500$ be the vehicle capacity of mode $1(\mathrm{~kg} /$ trip $), \ell_{111}=1$ be the binary parameter indicating that distribution center 1 is within an allowed distance from shelter 1 using mode 1. Finally, let $\beta_{111 s}=1$ be the binary parameter indicating that there is connectivity between distribution center 1 and shelter 1 by mode 1 in scenario $s$. Then, constraint (22) shows that $f_{1}^{\mathrm{w}} \cdot Z_{1111 s}+f_{2}^{\mathrm{w}} \cdot Z_{1112 s} \leq f_{1} \cdot \ell_{111} \cdot \beta_{111 s} \cdot Z_{111 s}^{\prime} \rightarrow 7.5 \cdot Z_{1111 s}+18.2 \cdot Z_{1112 s} \leq 2500 \cdot Z_{111 s}^{\prime}$. If the flow of products between distribution center 1 and shelter 1 using mode 1 is $Z_{1111 s}=1000$ for product 1 and $Z_{1112 s}=1000$ for product 2 , we have $Z_{111 s}^{\prime} \geq \frac{7500+18200}{2500}=10.28$. Therefore, the integer number of trips from distribution center 1 to shelter 1 using mode 1 is $Z_{111 s}^{\prime}=11$, considering that this variable is minimized in one of the objective functions. Now, let $\tau_{1}=8$ be the available number of trips per day per mode 1. Using the same set-up, constraint (23) gives $Z_{111 s}^{\prime} \leq 8 \cdot V_{111}$. If agency 1 allocates 10 vehicles (mode 1 ) to distribution center 1 , then this constraint limits the maximum number of trips from this distribution center to shelter 1 to 80 . Assume we have two scenarios, $s=1,2$, and let $\eta_{111}^{\mathrm{v}}=3$ and $\eta_{112}^{\mathrm{v}}=10$ be the total number of vehicles mode 1 that can be allocated by agency 1 in scenarios 1 and 2 , respectively. Therefore, constraint $(24)$ indicates that if agency 1 is activated $\left(W_{1}=1\right)$, then $V_{111} \leq 3$ and $V_{112} \leq 10$, implying that agency 1 cannot allocate more than 3 vehicles to distribution center 1 , since this decision must be done as part of the first-stage.

\section{The domain of the first-stage variables is as follows.}




$$
\begin{aligned}
W_{o} & \in\{0,1\}, \forall o \in \mathcal{O} \\
X_{i} & \in\{0,1\}, \forall i \in \mathcal{I} \\
Y_{j} & \in\{0,1\}, \forall j \in \mathcal{J} \\
V_{i m o} & \geq 0 \text { and integer, } \forall i \in \mathcal{I}, m \in \mathcal{M}, o \in \mathcal{O} \\
P_{\text {nio }} & \geq 0, \forall i \in \mathcal{I}, \quad n \in \mathcal{N}, o \in \mathcal{O} \\
Q_{o i}^{\mathrm{dc}} & \geq 0, \forall i \in \mathcal{I}, o \in \mathcal{O} \\
Q_{o i m}^{\mathrm{d}} & \geq 0, \forall i \in \mathcal{I}, m \in \mathcal{M}, o \in \mathcal{O} \\
Q_{o j}^{\mathrm{h}} & \geq 0, \forall j \in \mathcal{J}, o \in \mathcal{O} \\
Q_{o j}^{\mathrm{s}} & \geq 0, \forall j \in \mathcal{J}, o \in \mathcal{O} .
\end{aligned}
$$

Finally, the domain of the second-stage variables is as follows.

$$
\begin{aligned}
D_{j n s}^{\prime \prime} & \geq 0 \text { and integer, } \forall j \in \mathcal{J}, n \in \mathcal{N}, s \in \mathcal{S} \\
Z_{i j m n s} & \geq 0 \text { and integer, } \forall i \in \mathcal{I}, j \in \mathcal{J}, m \in \mathcal{M}, n \in \mathcal{N}, s \in \mathcal{S} \\
Z_{i j m s}^{\prime} & \geq 0 \text { and integer, } \forall i \in \mathcal{I}, j \in \mathcal{J}, m \in \mathcal{M}, s \in \mathcal{S} \\
D_{j s} & \geq 0, \forall j \in \mathcal{J}, s \in \mathcal{S} \\
D_{k j s}^{\prime} & \geq 0, \forall k \in \mathcal{K}, j \in \mathcal{J}, s \in \mathcal{S} \\
U_{j s}^{\mathrm{a}} & \geq 0, \forall j \in \mathcal{J}, s \in \mathcal{S} \\
U_{j s}^{\mathrm{h}} & \geq 0, \forall j \in \mathcal{J}, s \in \mathcal{S} \\
U_{j s}^{\mathrm{r}} & \geq 0, \forall j \in \mathcal{J}, s \in \mathcal{S} . \\
U_{k s}^{\mathrm{s}} & \geq 0, \forall k \in \mathcal{K}, s \in \mathcal{S} \\
U_{j n s}^{\prime} & \geq 0, \forall j \in \mathcal{J}, n \in \mathcal{N}, s \in \mathcal{S} .
\end{aligned}
$$

\section{SOLUTION PROCEDURE: THE $\epsilon$-CONSTRAINT METHOD}

In this paper we use the $\epsilon$-constraint method (Mavrotas, 2009) to solve the bi-objective model. Our choice was based on the manageability of this method to be implemented within decision support systems, since its application requires only the estimation of upper bounds 
for the cost-minimization objective. This task is assumed to be straightforward for our main practitioner, SINAPROC, which would need to analyze whether its residual budget can be used to further improve the disaster relief operations, thus mitigating the shortage risk. On the other hand, it would be more abstract for practitioners from SINAPROC to determine proper weights for the weighted sum method.

Roughly speaking, the $\epsilon$-constraint method relies on converting a multi-objective optimization problem into a single-objective optimization problem. This is performed by selecting one objective function as the primary goal, whereas the others are included in the problem as constraints, but bounded by a given value or ' $\epsilon$ '. In this way, we can control how much we are willing to deteriorate the remaining goals in exchange of having a good objective value for the primary goal. In our case, we consider that a minimum-solution shortage risk is our main goal so that the overall logistics costs are upper bounded by the initial costs plus the $\epsilon$ value, as follows:

$$
\begin{aligned}
& \min \operatorname{RISK}=\sum_{s \in \mathcal{S}} \pi_{s} \cdot\left[\frac{\sum_{j \in \mathcal{J}}\left(U_{j s}^{\mathrm{max}}+U_{j s}^{\mathrm{h}}+U_{j s}^{\mathrm{a}}\right)}{3}+\sum_{k \in \mathcal{K}} U_{k s}^{\mathrm{s}}\right], \\
& \text { s.t.: Constraints }(4)-(24) \\
& \mathrm{CosT} \leq \mathrm{CosT}^{\star}+\epsilon,
\end{aligned}
$$

in which $\operatorname{CosT}^{\star}$ can be the minimum cost solution. By parametrically varying the $\epsilon$ value the efficient solutions of the problem that trade-off shortage risk and logistics costs differently are then obtained (Mavrotas, 2009). Afterwards, decision-makers can choose the preferred solution among the different possibilities according to their risk preference. In this case, a more risk-averse decision-maker would prefer to have a solution with a lower risk of shortage even at the expense of higher logistics costs. Conversely, a less risk-averse decision-maker would rather choose a more balanced solution in which a higher risk of shortage is somehow compensated by relevant cost savings.

\section{THE CASE STUDY OF FLOODS IN MEXICO}

Hurricane Karl caused severe floods and several deaths in the State of Veracruz, Mexico, in September 2010. One of the most affected areas was the region Veracruz-Boca del Río. 
The region is located in the center of the State of Veracruz. It has an altitude of 10 meters above sea level and it is composed of 315 AGEBS (i.e. neighbourhoods) as shown in Figure 4, which represents the identification number of the AGEBs in different colours. This region is economically relevant because it hosts one of the most important ports of the country but its location makes it vulnerable to hurricanes and floods. Due to this disaster event, authorities declared a state of emergency in the State from 19 September 2010 to 19 October 2010, which posed a significant challenge for Mexico because a substantial proportion of Mexico's maritime trade is shipped from this area.

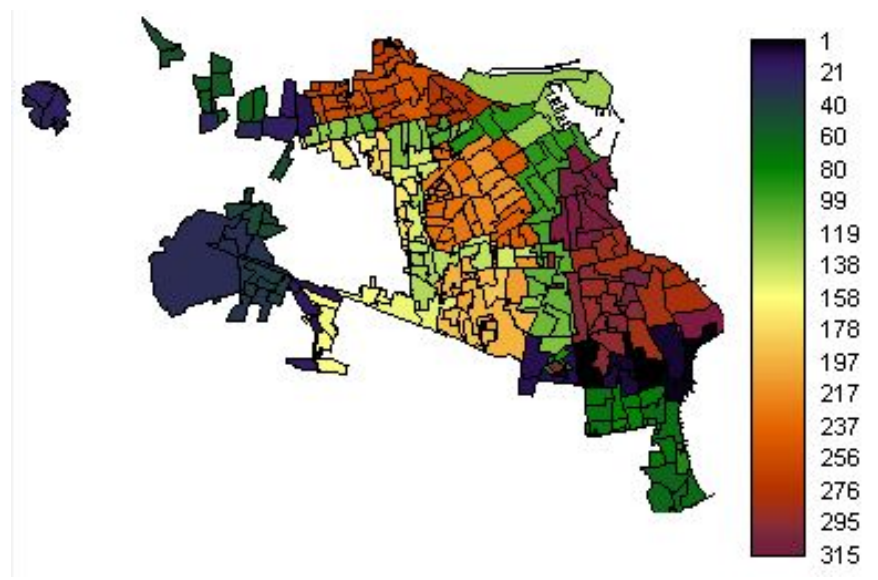

Figure 4: Veracruz-Boca del Río. (Source: INEGI (2012).

\subsection{Data Set}

We gathered information from nine government agencies involved in the disaster across health services (IMSS, SMEXICO and SVERACRUZ), food services (DICONSA), family services (DIF), military (SEDENA and SEMAR) and civil protection (PC and SEGOB), along with geographical information from the Mexican National Institute of Statistics and Geography (INEGI) and the United States Geological Survey (USGS). This information along with historical data about disasters in the region was used to estimate all the input data and to design a set of representative scenarios. For the sake of brevity, we will describe the main parameters associated with the agencies, facilities, and the conditions of the disaster. For additional details, please contact the corresponding author.

GIS preprocessing. This study considered two kinds of facilities; distribution centers which are used to prepositioning and dispatch the relief products and shelters that are used to house 
the victims. A total of 9 potential distribution centers and 43 candidate shelters were identified using Freedom of Information Requests (FOIs) to authorities, the shelter catalogue available, and the official website of the Ministry of Education (www.snie.sep.gob.mx/SNIESC/). The latter was used along with Google Maps $\AA$ and Bing Maps $\AA$ to visually confirm the locations. The geographical location of shelters and distribution centers in the area can be seen in the appendix, in Figures 11 and 12, respectively. The location of each facility was introduced in TRANSCAD® for network analysis.

Agency. Decision-making in disaster situations in Mexico is centralized, with SINAPROC as the coordinating body for disaster activities among different participants. As part of SINAPROC, Table 7 shows the agencies involved and their resources according to FOIs of the event caused by Hurricane Karl in 2010 and disaster management policies.

Table 7: Agency and their available resources

\begin{tabular}{cccccccc}
\hline Agency & Employees & \multicolumn{3}{c}{ Vehicles } & \multicolumn{2}{c}{ Relief products } \\
\hline & & Small & Medium & Large & Helicopter & Food & Medicines \\
DICONSA & 69 & 10 & 20 & 20 & 0 & 2500 & 0 \\
DIF & 60 & 5 & 1 & 5 & 0 & 0 & 0 \\
IMSS & 123 & 206 & 18 & 1 & 1 & 0 & 22 \\
PC & 36 & 35 & 19 & 0 & 1 & 0 & 0 \\
S. Mexico & 0 & 25 & 0 & 0 & 0 & 0 & 20 \\
S. Veracruz & 0 & 101 & 0 & 0 & 0 & 0 & 0 \\
SEDENA & 359 & 102 & 77 & 4 & 0 & 0 & 0 \\
SEGOB & 8 & 3 & 0 & 0 & 0 & 0 & 0 \\
SEMAR & 141 & 43 & 0 & 0 & 0 & 0 & 0 \\
\hline
\end{tabular}

Scenarios development. The proposed two-stage framework requires the evaluation of a set of scenarios that reflect the randomness associated with the following parameters: affected population $\left(\alpha_{k s}\right)$; connectivity between distribution centers and shelters $\left(\beta_{i j m s}\right)$; available personnel for distribution center operation $\left(\gamma_{o s}^{\mathrm{dc}}\right)$; available personnel for shelter operation $\left(\gamma_{o s}^{\mathrm{s}}\right)$; available teams for healthcare $\left(\gamma_{o s}^{\mathrm{h}}\right)$; available personnel for distribution $\left(\gamma_{o s}^{\mathrm{d}}\right)$; total operative personnel available $\left(\eta_{o s}^{\mathrm{p}}\right)$; total number of vehicles $\left(\eta_{m o s}^{\mathrm{v}}\right)$. To design plausible scenarios, we perform three steps:

Step 1. Historical data from previous floods in Veracruz was used to generate plausible realization for the number of victims. Table 8 shows the number of affected people in the 
previous disasters.

Table 8: Historical data of affected people allocated in shelters due to flood disasters in Veracruz, Mexico.

\begin{tabular}{lccccccccc}
\hline Year & 1993 & 1995 & 1999 & 2003 & 2005 & 2007 & 2010 & 2011 & 2013 \\
\hline No. of people & 20,553 & 5,000 & 21,990 & 5,538 & 5,434 & 22,225 & 12,476 & 3,935 & 2,367 \\
\hline
\end{tabular}

The figures in Table 8 were further categorized based on a territorial classification provided by the technical report published by Cervera and Rangel (2015). Table 9 shows the classification of the disasters, which occurred in the study area. The occurrence probability of each range is based on its relative frequency.

Table 9: Categorization of the affected people based on the real-data sample from flood disasters in Veracruz, Mexico.

\begin{tabular}{lcccc}
\hline $\begin{array}{l}\text { Range of } \\
\text { victims }\end{array}$ & $\begin{array}{c}\text { Number of } \\
\text { realizations }\end{array}$ & $\begin{array}{c}\text { Relative } \\
\text { frequency }\end{array}$ & Average & Median \\
\hline $0 \leq \mu<2,500$ & 1 & $11.11 \%$ & 2367 & 2367 \\
$2,500 \leq \mu<15,000$ & 5 & $55.56 \%$ & 6477 & 5434 \\
$15,000 \leq \mu<100,000$ & 3 & $33.33 \%$ & 21589 & 21990 \\
$100,000 \leq \mu$ & 0 & - & - & - \\
\hline
\end{tabular}

Step 2. In order to incorporate some variability in the small real-data sample, we first performed a distribution-fitting for our real-data sample using the input analyzer tool from the Arena simulation software. The result indicated that the Weibull distribution (with $\alpha=0.464, \beta=3,000$ and offset $=2,370)$ suited the data best. Afterwards, we simulated a sample of 10,000 realizations based on the proposed Weibull distribution and categorized them according to INEGI (2012), as illustrated in Table 10. It is worth noting that the simulated sample now contains some realizations that fall within the last range, which might be important to evaluate the preparedness decisions in very pessimistic scenarios.

Step 3. The proposed scenario-tree comprises the combination of the aforementioned eight random variables. The random affected population was approximated by the average and median values given by the simulation step illustrated in Table 10. As in the range $0 \leq \mu \leq 2,500$ median differs from the average value in $0.54 \%$, we only consider the worse realizations given by the average value. From the second range onwards, both average and median figures were used to compose the scenario-tree. In those cases, the probability of each 
Table 10: Categorization of the affected people based on the simulated sample.

\begin{tabular}{lcccc}
\hline $\begin{array}{l}\text { Range of } \\
\text { victims }\end{array}$ & $\begin{array}{c}\text { Number of } \\
\text { realizations }\end{array}$ & $\begin{array}{c}\text { Relative } \\
\text { frequency }\end{array}$ & Average & Median \\
\hline $0 \leq \mu<2500$ & 2013 & $20.13 \%$ & 2410 & 2397 \\
$2500 \leq \mu<15000$ & 6589 & $65.89 \%$ & 5882 & 4736 \\
$15000 \leq \mu<100000$ & 1333 & $13.33 \%$ & 27,309 & 24039 \\
$100000 \leq \mu$ & 65 & $0.6500 \%$ & 140415 & 125905 \\
\hline
\end{tabular}

range was split in two equiprobable realizations, e.g., both 5,882 and 4,736 have the same probability of occurrence equals to 0.32945 , totalling 0.6589 , which represents the probability of the range $2500 \leq \mu \leq 15000$.

In order to further generate the number of victims in each one of the 315 neighbourhoods shown in Figure 4, we use the information regarding their population. We then round up the obtained fractional numbers to the next integer values based on the perspective that it is better to hedge against worst-case values for the number of victims. This caused the minor differences in the number of victims shown in Figure 5. For the remaining resources variables, we investigate the current situation of the organizations and three possible alternatives were considered: pessimistic, realistic, and optimistic. The realistic values refer to the resources that the agency owned at the time, the pessimistic and optimistic values refer to a percentage $20 \%$ below and above from the realistic values, respectively. For the available personnel for distribution center operation and distribution, though, we generated only two options because there is no option for increasing the number of workers. Thus, realistic and pessimistic values (20\% below) were introduced. If the number of victims is 4,893 and if the expectation of the resources is pessimistic, thus this combination provides the fourth scenario of the scenario-tree depicted in Figure 5. 


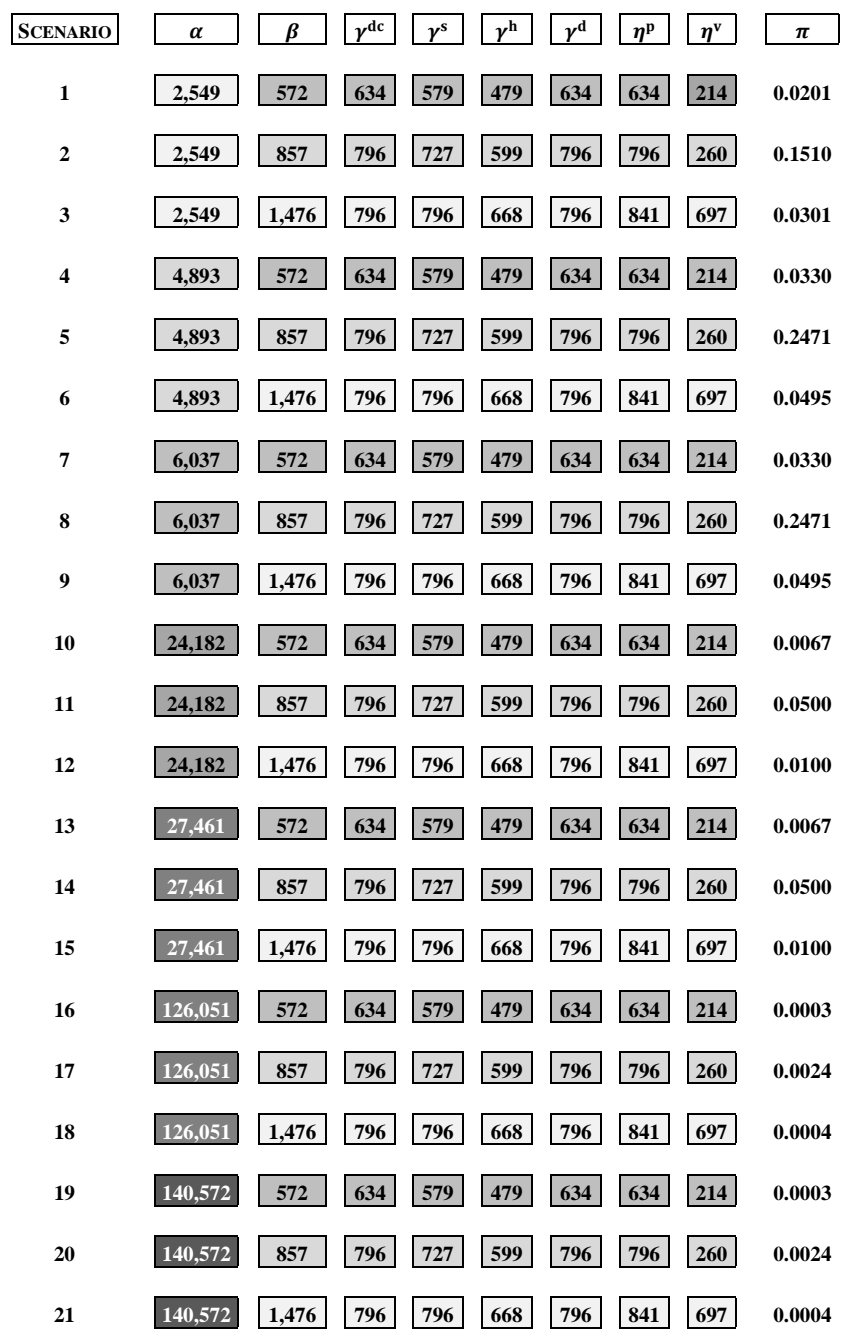

Figure 5: Scenarios comprising the affected population and the seven aforementioned parameters related to resources. All the figures refer to the aggregate values over zones, agencies, and so forth. Note. Darker scenarios indicate more pessimistic ones.

\subsection{Results and discussion}

The optimization model was coded into GAMSß 24.0.2 using CPLEX® 12.5 as default solver. The stop criteria for the branch-and-cut algorithm of the CPLEX was set at 3600 seconds and/or $1 \%$ of relative gap. All the tests were performed on a machine with Intel $\mathbb{R}$ Core $^{\mathrm{TM}}$ i7computer with 16 gigabyte RAM and MS-Windows 7 operating system. The main objective of the numerical evaluation is to analyse the results of the optimization models, thus providing relevant managerial implications that can be discussed further with diverse Mexican authorities in an attempt to improve the current disaster preparedness management 
in the country.

The Pareto frontier obtained from solving the model for the instances presented can be seen in Figure 6, which depicts the tradeoffs between objective functions. A total of 13 points were obtained using the $\epsilon$-constraint. The impact of those trade-offs is very important. For instance, between points 4 and 5, an investment of over MXP 500,000 represents aid for 861 people. However, between points 10 and 11, the same investment would have a difference of only 24 people across all scenarios. This serves as an example of the value of multi-objective approaches.

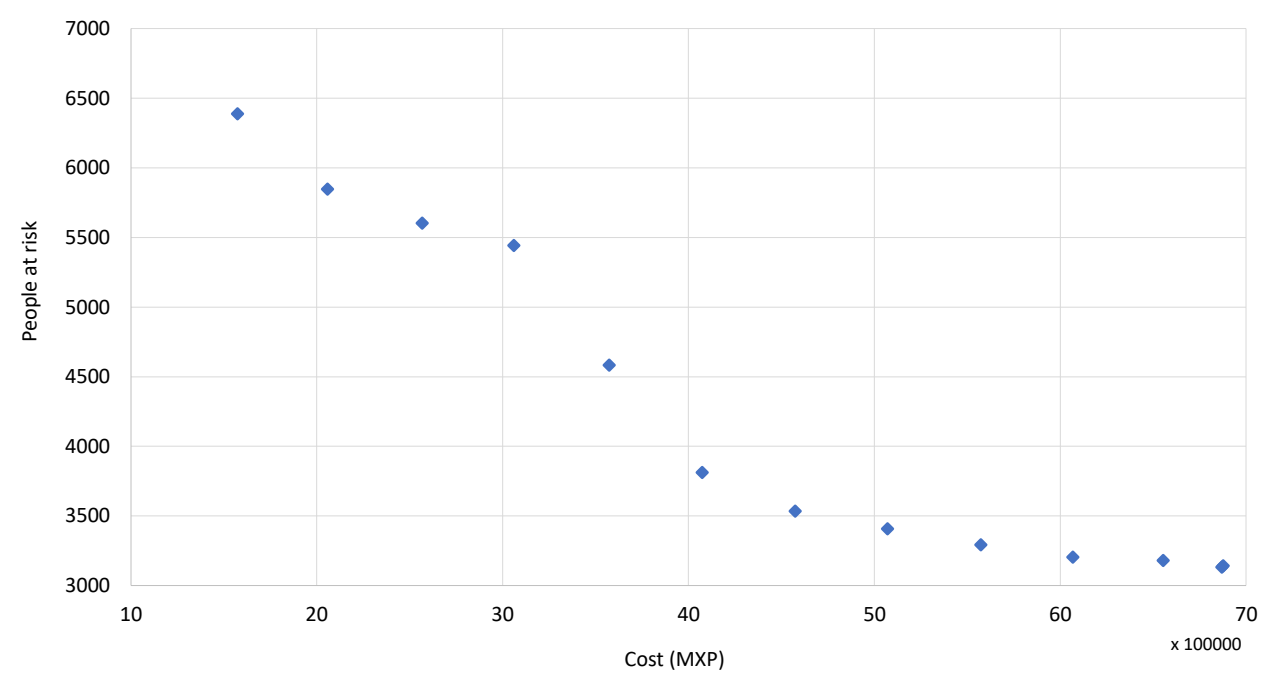

Figure 6: Pareto Frontier of the stochastic model

Table 11 shows an overview of some relevant results. There is a trend of increasing facilities and agencies in solutions which have increased investment, which is reflected in reduced shortage risk.

Figure 7 shows the number of victims without each type of assistance, namely, healthcare, attention, relief aid, and shelter, for each solution of the $\epsilon$-constraint method across all scenarios. In an attempt to mitigate the overall shortage for assistance, the number of people without attention and relief aid increases substantially at the same time as the number of people without shelter reduces dramatically. This is because, as more people enter shelters, the demand of products and services in shelters increases, thereby increasing the potential number of people who cannot be completely served in there. However, please note the scale 
Table 11: Summary of the results of the Pareto frontier

\begin{tabular}{cccccc}
\hline Iteration & CosT & $\begin{array}{c}\text { RISK } \\
\text { (people) }\end{array}$ & $\begin{array}{c}\text { Number of } \\
\text { DCs }\end{array}$ & $\begin{array}{c}\text { Number of } \\
\text { shelters }\end{array}$ & $\begin{array}{c}\text { Number of } \\
\text { agencies }\end{array}$ \\
\hline 1 & $1,573,183$ & 6,388 & 3 & 5 & 3 \\
2 & $2,058,174$ & 5,849 & 2 & 9 & 5 \\
3 & $2,567,864$ & 5,605 & 2 & 15 & 5 \\
4 & $3,060,418$ & 5,445 & 2 & 7 & 5 \\
5 & $3,573,696$ & 4,584 & 2 & 11 & 7 \\
6 & $4,073,597$ & 3,813 & 2 & 15 & 5 \\
7 & $4,573,649$ & 3,536 & 4 & 15 & 5 \\
8 & $5,069,961$ & 3,409 & 3 & 21 & 7 \\
9 & $5,573,625$ & 3,293 & 4 & 26 & 8 \\
10 & $6,068,641$ & 3,204 & 3 & 37 & 8 \\
11 & $6,553,219$ & 3,181 & 3 & 28 & 8 \\
12 & $6,877,528$ & 3,143 & 4 & 40 & 8 \\
13 & $6,869,193$ & 3,134 & 3 & 39 & 8 \\
\hline
\end{tabular}

in each section. The increase in risk of shortage of shelter care and relief is far lower than the corresponding increase on the number of people allocated to shelters. Despite that, the results show that healthcare becomes a priority because of the trade-off between objectives. Adding one extra healthcare employee has more impact in the number of people served compared to shelter personnel and relief sent and it is more cost-effective.
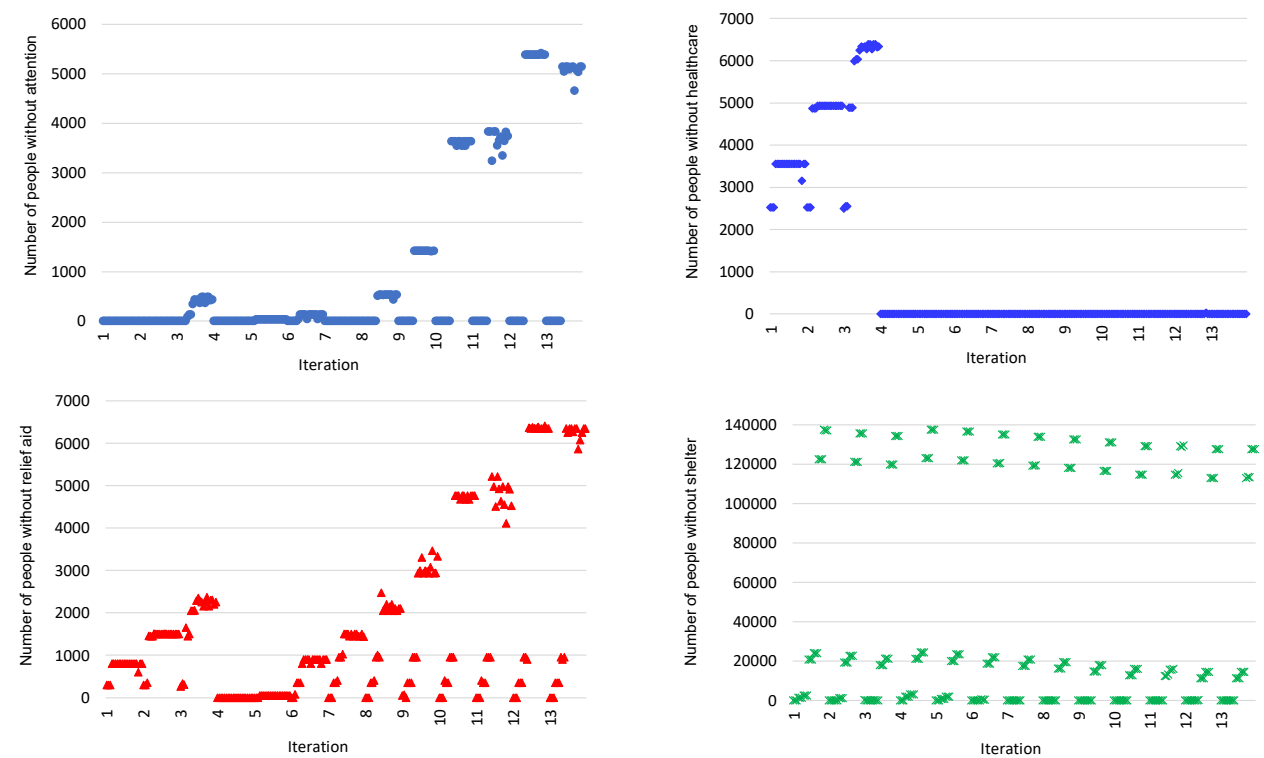

Figure 7: Number of victims without healthcare, attention, relief aid, and shelter for all the 13 iterations of the method. For each iteration, we plot the solution for all the 21 scenarios. 
It is expensive to activate shelters, which is the reason cheaper solutions include fewer facilities compared to more service oriented solutions, as shown in Table 11. Figure 8 displays the most used shelters in the area across iterations contrasted with the population of each area. Most of the shelters are located towards the center with the purpose to provide a good balance of capacity and safety for the most populated areas in the north and center. There are also a couple of facilities serving the highly populated areas in the south. Investment in these facilities to ensure they are readily available and in good conditions would be relevant to ensure immediate reaction to a disaster.

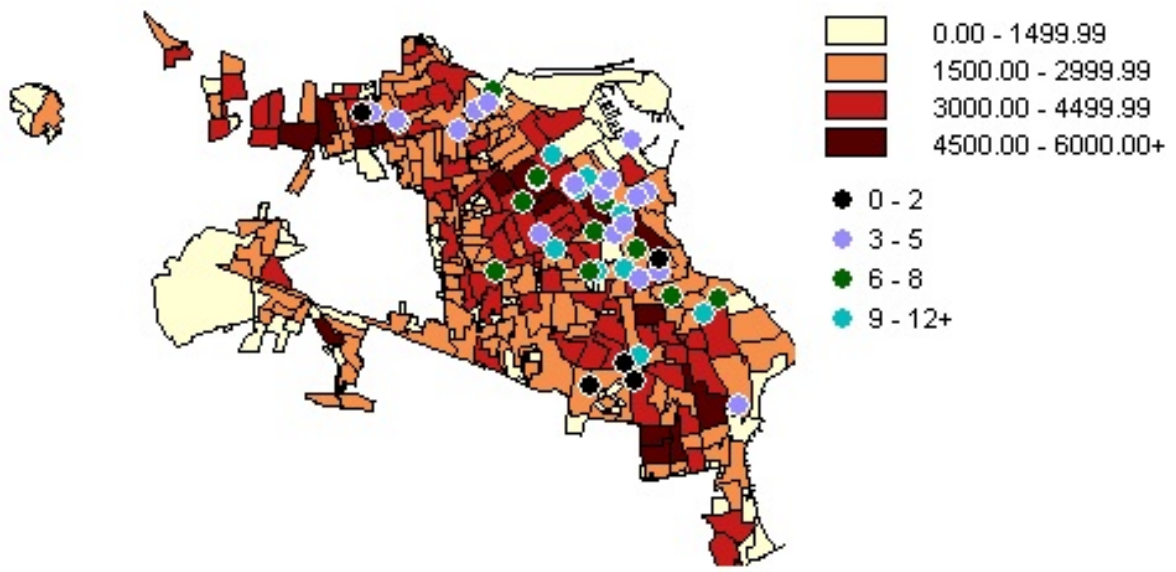

Figure 8: Frequency of shelter activation. The squares represent the AGEBs, whereas the circles show the potential location of shelters.

Relief distribution requires facilities, people, products, and vehicles. Similar to the case of shelters, Table 11 shows an increasing number of distribution centers for service-oriented solutions. Figure 9 introduces the frequency of selection of the distribution centers across the 13 iterations contrasted with the population per area. Distribution centers in use are in different areas, but the most used one is in the city center. This is due to connectivity and the level of coverage required to deliver relief, with more possibility to timely serve the different areas from the center. Beyond that facility, more investment in distribution centers represents a benefit to surrounding areas because more facilities are activated closer to them. 


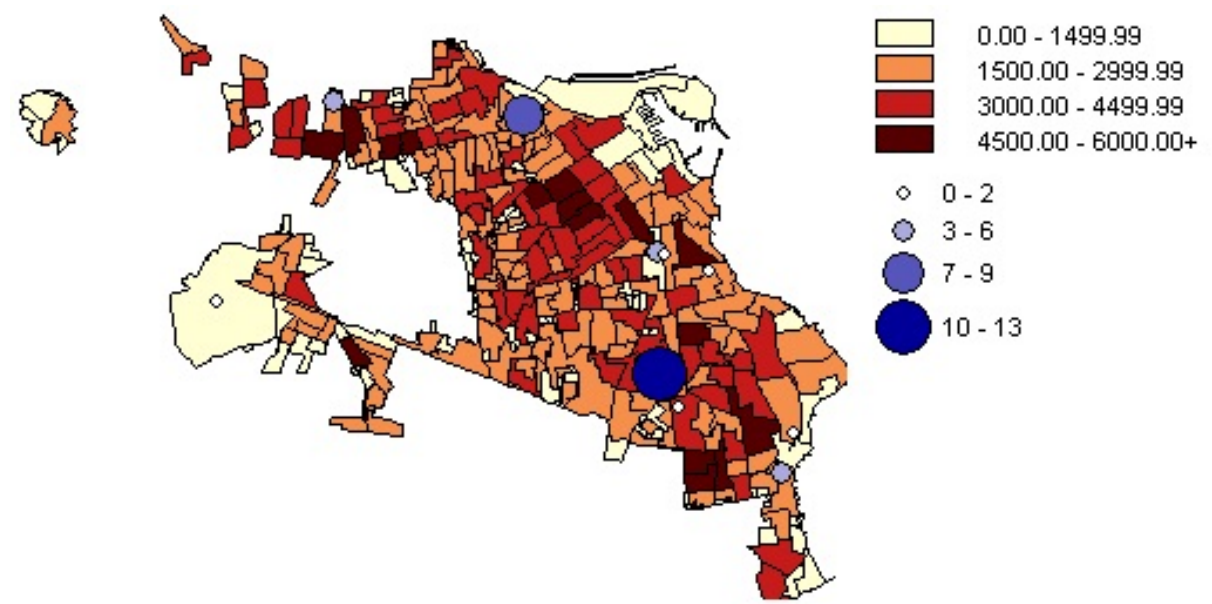

Figure 9: Frequency of distribution center activation. The squares represent the AGEBs, whereas the circles show the potential location of distribution centers.

A key feature of the formulation provided is the potential to manage the number of agencies deployed to the field to prevent supply congestion. From the point of view of the coordinating organization, this feature makes it possible to focus on the resources required in the disaster and allow other agencies to perform their regular activities. In fact, this aligns to the response policy of different national disaster systems such as the one(s) in Mexico. These systems favour deploying agencies by layers based on the severity of the disaster.

As it can be seen in Table 11, the number of agencies increases in more service-oriented solutions when compared to cheaper solutions. Evidently, cost increases more rapidly than the corresponding reduction in the number of people at risk, but this table shows that after 5 agencies are deployed, the potential improvement of involving more participants is lower, whereas cost increases considerably. This result suggests that the involvement of agencies should be carefully analysed considering the cost-benefit ratio. Although it can be rather expensive to provide an increased relief assistance, some solutions exhibit quite an interesting trade-off. For example, it is possible to improve the overall relief assistance by almost $17 \%$ at the expense of less than $14 \%$ in the logistics costs; this result is due to iteration 6 of the $\epsilon$-constraint method (see Figure 13 in the appendix for further details).

Considering the added complexity in collaboration generated by having an elevated number of participants, it is important to have only the right expertise in place. Auf der Heide and Irwin (1989) argued that excessive supply can create logistics issues because of conges- 
tion. This is further complicated by the uncertainty on the supply of human and material resources experienced in disasters (Rodríguez-Espíndola et al, 2020). Incorporating that dimension into the optimization model makes it possible to have a more realistic view of the participants required to reduce the possibility of not only shortages, but also excess. This has relevant implications for decision-making because the solutions delivered by the model are more reliable, which can serve to introduce another degree of realism to the model. In the results of the model, there is a high level of expertise in terms of healthcare, but not enough staff was available to provide shelter attention despite the number of employees allocated to that activity. The result from 7 shows the need to introduce more operative support to activate and manage shelters.

The number of participant agencies also affects transportation decisions. Ranging from cheaper to service-oriented solutions, the number of used vehicles increased as part of the added investment and the inclusion of more participants (See figure 14 in the appendix). In general, the solutions show that different types of vehicles can be used depending on the resources available, which leads to the belief that heterogeneous fleets can be valuable in these circumstances. The reason for this is that the variation in terms of distance (range of the vehicles), the infrastructure state, fleet ownership, and the type of demand areas require heterogeneous capabilities from the vehicle fleet.

\section{ARE THERE BENEFITS OF USING THE TWO-STAGE STOCHASTIC APPROACH?}

In this section, we show that the proposed two-stage stochastic programming approach brings benefits to the analysis of the disaster preparedness problem under study. Moreover, we prove that working with simpler approaches might not be a good idea if the mitigation of people-at-risk is the primary goal. Traditionally, the relevance of two-stage stochastic formulations is measured in terms of their relative performance in comparison to deterministic ('simpler') approaches. Mathematically, this is done through the analyses of both the Expected Value of Perfect Information (EVPI) and the Value of Stochastic Programming (VSS).

Let us assume that the Mexican Civil Protection National Council (SINAPROC) has per- 
fect and accurate information on the victims needs and overall supplies/resources beforehand the next potential disaster. In this case, we can solve a deterministic problem based on the information given by scenario $s$, for example, in order to determine the optimal preparedness plan for this specific situation. To simulate how good our decisions would be with perfect information, we solve an optimization problem for each scenario $s$, which is the so-called Wait-and-See (WS) problem whose corresponding optimal value is given by $z_{s}^{\text {WS }}$. In our case, we would have 21 deterministic problems to solve as a result of our developed scenarios. By taking the expectation over the 21 scenarios, we obtain the expected wait-and-see value, given by $z^{\mathrm{WS}}=\sum_{s \in \mathcal{S}} \pi_{s} \cdot z_{s}^{\mathrm{WS}}$. Finally, EVPI is computed as the difference between the objective function of the stochastic model $\left(z^{\mathrm{RP}}\right)$ and the expected wait-and-see solution $\left(z^{\mathrm{WS}}\right)$, i.e., $\mathrm{EVPI}=z^{\mathrm{RP}}-z^{\mathrm{WS}}$. As our problem focuses on the minimization of the number of victims without assistance, EVPI yields the number of people to whom we would be able to provide further assistance if perfect information is available.

If we replace all stochastic parameters by their average values, we end up with a deterministic optimization problem, usually called The Expected Value Problem (EV). EV is generally easier to solve than the the two-stage stochastic programming problem (RP). However, using the EV solution means that we will not take advantage of the information given by each disaster scenario, nor its corresponding probability. Therefore, it would not be possible to take actions towards minimizing people-at-risk according to each outcome of the random variables. VSS precisely assesses the effectiveness of the EV solution. For this purpose, we solve the two-stage stochastic programming problem (RP) and the Expect Result of Using the EV Solution, or simply EEV problem, and compute their corresponding objective values $z^{\mathrm{RP}}$ and $z^{\mathrm{EEV}}$. It is worth noting that both EEV and RP exhibit the same mathematical structure, but EEV is a simplified version in which all its first-stage variables are pre-fixed according to the EV optimal solution. Thus, optimizing EEV means determining only the optimal second-stage decisions. Mathematically, VSS $=z^{\mathrm{EEV}}-z^{\mathrm{RP}}$ shows how good the RP approach is in terms of mitigating the shortage risk in comparison to the expected value approach.

Table 12 summarizes the main results for both metrics. For all iterations, we have $\mathrm{RP}>\mathrm{WS}-$ bear in mind all values are given in number of victims -, showing that 
randomness plays an important role in our problem regardless the fact the minimization is in favour of costs or shortage risk. Under perfect information, we could provide further humanitarian assistance to 206 victims on average, which corresponds to almost $5 \%$ of the shortage risk function. In the worst-case (best-case) scenario, the WS approach is able to fulfil 564 (95) more victims in comparison to the stochastic solution. The analysis of the (sub)optimal shortage risk objectives given by RP and WS shows that incrementing the financial budget iteratively has a stronger (better) effect in the RP than in the deterministic WS problem. In fact, notice that the risk of not satisfying victims needs decreases slightly faster in RP than in WS, with the exception of the first few iterations. This behaviour is illustrated in Figure 10. Since EV and WS are both deterministic approaches, their behaviours are similar, unless in some iterations in which EV experienced relatively high optimality gaps, e.g., in the 9th iteration.

Remarkably, all the EEV problems turned out to be infeasible when the first-stage decisions were fixed according to the EV solutions. Therefore, taking preparedness decisions based on a single expected value instead of on the proposed set of scenarios dramatically increases the shortage risk. Mathematically, we represent VSS $\rightarrow+\infty$ to emphasise that the risk is infinitely higher in $\mathrm{EV}$ than in $\mathrm{RP}$, which makes sense from the practical point of view, as humanitarian assistance cannot be performed in light of the EV solution. One way to find feasible values for EEV, though, relies on relaxing part of the first-stage decision variables given by the EV problem. Therefore, we re-solve EEV by unfixing $Q_{o i}^{d c}, Q_{o i m}^{a}, Q_{o j}^{s}, Q_{o j}^{h}$, and $V_{i m o}$, thus keeping the remaining first-stage decision variables $X_{i}, Y_{j}, W_{o}$, and $P_{n i o}$ fixed. The resulting EEV problem was feasible for all the iterations, suggesting that the number of personnel and vehicles has a direct impact on the implementability of the expected value solution, unlike the location and prepositioning decisions. In practice, making decisions according to the average number of victims and resources would imply more resources and, thus, the risk of not assisting victims with a proper assistance would be higher. 
Table 12: Summary of the results associated with both metrics EVPI and VSS.

\begin{tabular}{ccccccccc}
\hline Iteration & $\mathrm{RP}^{\star}$ & $\mathrm{WS}^{\star \star}$ & $\mathrm{EVPI}$ & $\mathrm{EV}^{\star \star \star}$ & $\mathrm{EEV}$ & $\mathrm{VSS}$ & $\mathrm{EEV}^{\dagger}$ & $\mathrm{VSS}^{\dagger}$ \\
\hline 1 & 6388 & 6,134 & 255 & 5,184 & Infeasible & $+\infty$ & 6,535 & 147 \\
2 & 5849 & 5,544 & 305 & 4,386 & Infeasible & $+\infty$ & 6,019 & 171 \\
3 & 5605 & 5,233 & 372 & 3,788 & Infeasible & $+\infty$ & 5,582 & - \\
4 & 5445 & 4,881 & 564 & 3,080 & Infeasible & $+\infty$ & 5,564 & 120 \\
5 & 4584 & 4,156 & 428 & 3,253 & Infeasible & $+\infty$ & 5,506 & 923 \\
6 & 3813 & 3,703 & 110 & 2,868 & Infeasible & $+\infty$ & 5,489 & 1,675 \\
7 & 3536 & 3,441 & 95 & 1,599 & Infeasible & $+\infty$ & 3,639 & 103 \\
8 & 3409 & 3,299 & 110 & 718 & Infeasible & $+\infty$ & 3,423 & 14 \\
9 & 3293 & 3,187 & 106 & 7,752 & Infeasible & $+\infty$ & 7,304 & 4,011 \\
10 & 3204 & 3,102 & 102 & 1,113 & Infeasible & $+\infty$ & 3,352 & 148 \\
11 & 3181 & 3,076 & 104 & 720 & Infeasible & $+\infty$ & 3,214 & 33 \\
12 & 3143 & 3,029 & 115 & 702 & Infeasible & $+\infty$ & 3,190 & 47 \\
13 & 3134 & 3,031 & 103 & 702 & Infeasible & $+\infty$ & 3,185 & 51 \\
\hline Average & 4,199 & 3,986 & 213 & 2,759 & - & - & 4,769 & 620 \\
Minimum & 3,134 & 3,029 & 95 & 702 & - & - & 3,185 & 14 \\
Maximum & 6,388 & 6,134 & 564 & 7,752 & - & - & 7,304 & 4,011 \\
\hline
\end{tabular}

* Maximum elapsed time of 14,400 seconds per iteration; Average optimality gap of $0.7805 \%$; ${ }^{\star}$ Maximum elapsed time of 3,600 seconds per iteration and subproblem; Average optimality gap of $1.475 \%$; ${ }^{\star \star \star}$ Maximum elapsed time of 3,600 seconds per iteration; Average optimality gap of $11.29 \%$.

$\dagger$ Approximate EEV and VSS via relaxing the fixation of $Q_{o i}^{d c}, Q_{o i m}^{a}, Q_{o j}^{s}, Q_{o j}^{h}$, and $V_{i m o}$. The average optimality gap is $0.8571 \%$ in this case. 


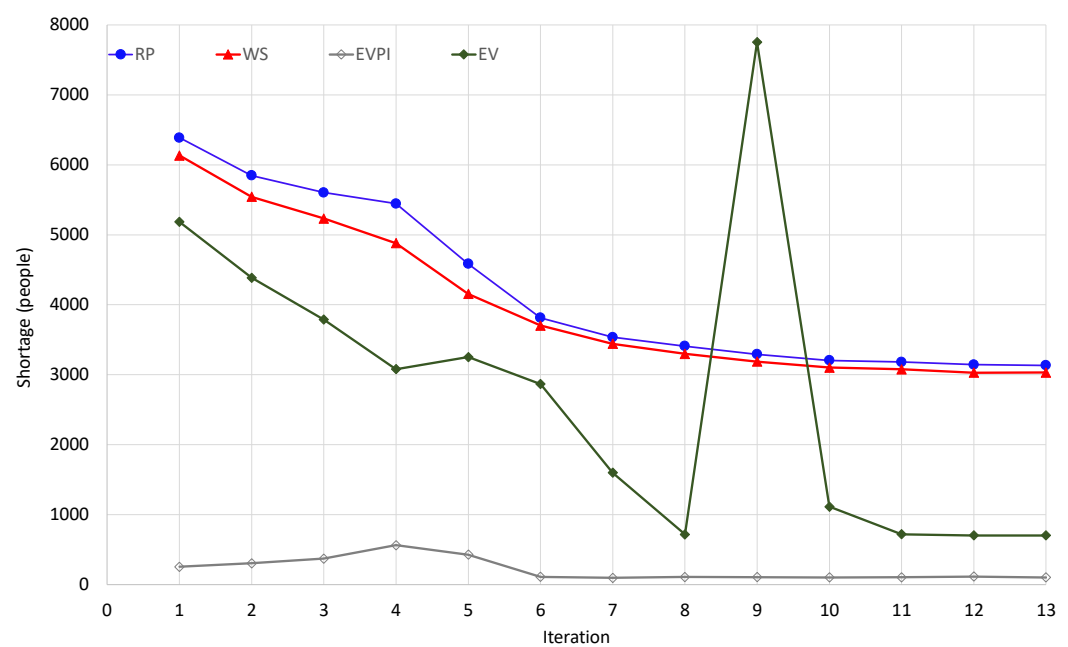

Figure 10: Relationship between the shortage risk given by RP, WS, EV, and EVPI approaches.

\section{CONCLUDING REMARKS}

The risk of shortage of products in disaster relief has been commonly addressed in the literature, but the risk of shortage of services needs further investigation, especially in a multi-disciplinary context. This study has proposed a novel multi-agency stochastic model for disaster preparedness considering the balance between cost and people-at-risk as consequence of the shortage of human and material resources necessary to alleviate victims in the aftermath of a disaster. The formulation supports typical preparedness and response decisions related to the selection of facilities, stock pre-positioning, relief distribution and organization management in a stochastic environment with uncertainty in several supply sources and victims' needs.

A set of scenarios was generated for analysis based on the flood of Veracruz, Mexico, in 2010. Tests based on 21 variants of the scenario show the capability of the model to balance resources whilst serving different areas. The results show the value of integrating uncertainty into a multi-agency setting for disaster management. In fact, if perfect and accurate information were available, it would be possible to assist almost $5 \%$ more of the overall people-at-risk, which is far from negligible in dealing with a humanitarian supply chain. Remarkably, we found that making preparedness decisions based on expected values leads to infeasible solutions in several scenarios, thus undermining the effectiveness of the relief operations. 
The model solution shows how integrating the decision of the number of agencies can contradict the instinct of sending all of the resources possible to the affected area. Even when uncertainty was accounted for, the solutions of the model suggest that the peopleat-risk can be significantly reduced with fewer agencies than the number available. This is because in most cases participants have a certain expertise, which makes them valuable for specific activities. Therefore, depending on demand, agencies were activated based on their capabilities and resources, preventing the deployment of unnecessary participants. In practice, this can reduce supply congestion and allow to decrease the disruption generated by having to force agencies to temporarily leave their normal activities to help in the emergency.

Additionally, the results show the trade-off between cost and people-at-risk, which is faced by decision-makers. The bi-objective nature of the model was justified by these trade-offs, which shows that the impact of investment in more service-oriented solutions was not nearly as efficient as it was for cheaper solutions. This finding can help authorities to identify the need for balance between both measures and incorporate it in their decisions.

The model has the potential to support decision-making under different conditions. Introducing uncertainty in demand, supply, and connectivity can provide more confidence in the suggestions coming from the results. In most disaster situations, resources are scarce and information imperfect, circumstances in which the model proposed in this research can provide support. This was the case in the instance presented, in which the available resources were not enough to fulfil the needs of the different scenarios. Under those circumstances, the results showed the value of considering services in shelters (shelter care and healthcare) because of the human resources required for these activities, which limit the number of employees available for other initiatives. In that sense, it can be noted that medical care seems to be one of the priorities of Mexican authorities, as they currently seem to have enough medical teams to cover different scenarios. Conversely, more emphasis must be placed on planning for shelters and human resources to handle these facilities, as the results showed shortages of employees to open more facilities and limited availability of pre-approved shelters. Similarly, the stock prepositioning policy should be revised to prepare for a wider range of circumstances.

We have applied the state-of-the-art branch-and-cut (B\&C) method implemented in 
CPLEX 12.5 for solving the $\epsilon$-constraint iterations. Therefore, we ensure that the obtained solutions are optimal or within $1 \%$ of the optimal solution within plausible running times. Notice that, considering that our disaster timeline is given in weeks, it might be acceptable to have the optimal solutions after a couple of hours. We acknowledge, though, that it would be first n ecessary to i mplement o ur a pproach in o pen s ource solvers to allow their free use by relief agencies, as well as to build a user-friendly interface to make it more appealing for supporting pre-disaster decisions in practical humanitarian contexts. For this purpose, we understand that speeding-up the solution approach might be desirable and this could be done through heuristics and metaheuristics based on the problem decomposition, such as in Moreno et al $(2019,2020)$, which can be a promising future research. Also, as our model is particularly relevant from the multi-agency coordination viewpoint, it would be insightful to test it in assisting logistics decisions when there are different types of disasters occurring simultaneously. In such cases, the uncertain nature of the concurrent disasters naturally imposes additional challenges for coordination and resources deployment.

\section{REFERENCES}

Adida E, DeLaurentis PC, Lawley M (2011) Hospital stockpiling for disaster planning.

IIE Transactions 43(5):348 - 362, URL http://search.ebscohost.com/login.aspx? direct=true\&db=bth\&AN=59165446\&s ite=eds -1 ive\&authtype=ip, shib\&custid= s9815128

Adivar B, Atan T, Sevil Oflaç B, Örten T (2010) Improving social welfare chain using optimal planning model. Supply Chain Management: An International Journal 15(4):290-305

Ahmadi M, Seifi A, Tootooni B (2015) A humanitarian logistics model for disaster relief operation considering network failure and standard relief time: A case study on San Francisco district. Transportation Research Part E 75:145-163 
Alem D, Clark A, Moreno A (2016) Stochastic network models for logistics planning in disaster relief. European Journal of Operational Research 255(1):187 - 206

Alexander DE (2015) Evaluation of civil protection programmes, with a case study from mexico. Disaster Prevention Management 24(2):263, URL http: //search. ebscohost.com/login. aspx?direct=true\&db=edb\&AN=101529285\&site= eds-live\&authtype $=i p$, shib\&custid $=$ s 9815128

Ali Torabi S, Shokr I, Tofighi S, Heydari J (2018) Integrated relief pre-positioning and procurement planning in humanitarian supply chains. Transportation Research Part E 113(Making connections: Supply chain innovation research collaboration;):123 - 146, URL http://search. ebscohost. com/login. aspx?direct=true\&db=edselp\&AN= S1366554517310177\&site=eds-live\&authtype=ip, shib\&custid=s9815128

Alinaghian M, Aghaie M, Sabbagh MS (2019) A mathematical model for location of temporary relief centers and dynamic routing of aerial rescue vehicles. Computers \& Industrial Engineering 131:227 - 241

Arif A, Wang Z, Chen C, Chen B (2020) A stochastic multi-commodity logistic model for disaster preparation in distribution systems. IEEE Transactions on Smart Grid, Smart Grid, IEEE Transactions on, IEEE Trans Smart Grid 11(1):565 576, URL http://search.ebscohost.com/login. aspx?direct=true\&db=edseee\&AN= edseee $.8750846 \&$ site=eds - live\&authtype=ip, shib\&custid=s 9815128

Balcik B, Beamon BM, Krejci CC, Muramatsu KM, Ramirez M (2010) Coordination in humanitarian relief chains: Practices, challenges and opportunities. International Journal of Production Economics 126(1):22 - 34

Balcik B, Silvestri S, Rancourt M Laporte G (2019) Collaborative prepositioning network design for regional disaster response. Production and Operations Management 28(10):24312455, DOI 10.1111/poms.13053, URL https://onlinelibrary.wiley.com/doi/abs/10. 1111/poms.13053, https://onlinelibrary.wiley.com/doi/pdf/10.1111/poms.13053 
Barbarosoglu G, Ozdamar L, Cevik A (2002) An interactive approach for hierarchical analysis of helicopter logistics in disaster relief operations. European Journal of Operational Research 140(1):118 - 133

Beamon Benita M, Balcik B (2008) Performance measurement in humanitarian relief chains. International Journal of Public Sector Management 21(1):4 - 25, URL http: //search. ebscohost. com/login. aspx?direct=true\&db=edsemr\&AN=edsemr. 10 . $1108.09513550810846087 \&$ site=eds-live\&authtype=ip, shib\&custid=s9815128

Caunhye AM, Nie X, Pokharel S (2012) Optimization models in emergency logistics: A literature review. Socio-Economic Planning Sciences 46(1):4 - 13, URL http://search.ebscohost.com/login. aspx?direct=true\&db=edselp\&AN= S0038012111000176\&site=eds-live\&authtype=ip, shib\&custid=s9815128

Çelik M, Ergun Ö, Johnson B, Keskinocak P, Lorca Á, Pekgün P, Swann J (2012) Humanitarian Logistics, chap 3, pp 18-49. DOI 10.1287/educ.1120.0100, URL http: //pubsonline.informs.org/doi/abs/10.1287/educ.1120.0100, http://pubsonline. informs.org/doi/pdf/10.1287/educ.1120.0100

Celik E, Aydin N, Gumus AT (2016) A stochastic location and allocation model for critical items to response large-scale emergencies: A case of turkey. An International Journal of Optimization and Control: Theories Applications 7(1):1 - 15, URL http://search. ebscohost. com/login. aspx?direct=true\&db=edsdoj\&AN=edsdoj . 3f6f4b09a0d42ccb64a1a8290da853e\&site=eds-live\&authtype=ip, shib\&custid= s9815128

Cervera M, Rangel W (2015) Distribución de la población por tamano de localidad y su relación con el medio ambiente. Available in http://www.inegi.org.mx/eventos/2015/Poblacion/doc/p-WalterRangel.pdf. Accessed online 30 Dec 2015

Chen AY, Peña-Mora F, Ouyang Y (2011) A collaborative GIS framework to support equipment distribution for civil engineering disaster response operations. Automation in Construction 20(5):637 - 648 
Chou JS, Tsai CF, Chen ZY, Sun MH (2014) Biological-based genetic algorithms for optimized disaster response resource allocation. Computers \& Industrial Engineering 74:5267

Döyen A, Aras N, Barbarosoğlu G (2012) A two-echelon stochastic facility location model for humanitarian relief logistics. Optimization Letters 6(6):1123-1145

Falasca M, Zobel C (2012) An optimization model for volunteer assignments in humanitarian organizations. Socio-Economic Planning Sciences 46(4):250 - 260

Gossler T, Wakolbinger T, Nagurney A, Daniele P (2019) How to increase the impact of disaster relief: A study of transportation rates, framework agreements and product distribution. European Journal of Operational Research 274(1):126 - 141, DOI https://doi.org/10. 1016/j.ejor.2018.09.045, URL http://www.sciencedirect.com/science/article/pii/ S0377221718308270

Grass E, Fischer K (2016) Two-stage stochastic programming in disaster management: A literature survey. Surveys in Operations Research and Management Science 21(2):85 - 100

Gu J, Zhou Y, Das A, Moon I, Lee GM (2018) Medical relief shelter location problem with patient severity under a limited relief budget. Computers \& Industrial Engineering 125:720 $-728$

Gupta S, Starr MK, Farahani RZ, Matinrad N (2016) Disaster management from a pom perspective: Mapping a new domain. Production Operations Management 25(10):1611 - 1637, URL http://search.ebscohost.com/login.aspx?direct=true\&db=bth\&AN= 118687692\&site=eds-live\&authtype=ip, shib\&custid $=$ s9815128

Haimes YY (2012) Strategic preparedness for recovery from catastrophic risks to communities and infrastructure systems of systems. Risk Analysis 32(11):1834-1845

Auf der Heide E, Irwin R (1989) Disaster Response: Principles of Preparation and Coordination. Mosby 
Holguín-Veras J, Jaller M, Van Wassenhove LN, Pérez N, Wachtendorf T (2012) On the unique features of post-disaster humanitarian logistics. Journal of Operations Management 30(7):494-506

Holguín-Veras J, Pérez N, Jaller M, Wassenhove] LNV, Aros-Vera F (2013) On the appropriate objective function for post-disaster humanitarian logistics models. Journal of Operations Management 31(5):262 - 280, DOI https://doi.org/10.1016/j.jom.2013.06.002, URL http://www.sciencedirect.com/science/article/pii/S0272696313000417

Hoyos MC, Morales RS, Akhavan-Tabatabaei R (2015) OR models with stochastic components in disaster operations management: A literature survey. Computers \& Industrial Engineering 82:183 - 197

Hu S, Dong ZS (2019) Supplier selection and pre-positioning strategy in humanitarian relief. Omega 83:287 - 298, URL http://search.ebscohost.com/login.aspx?direct= true\&db=edselp\&AN=S0305048318305358\&site=eds - live\&authtype=ip, shib\&custid= s9815128

Hu SL, Han CF, Meng LP (2015) A scenario planning approach for propositioning rescue centers for urban waterlog disasters. Computers \& Industrial Engineering 87:425 - 435

Hu SL, Han CF, Meng LP (2017) Stochastic optimization for joint decision making of inventory and procurement in humanitarian relief. Computers \& Industrial Engineering 111:39 $-49$

INEGI (2012) INEGI Scince versión 05/2012. Available in http://www.inegi.org.mx/est/scince/scince2010.aspx. Accessed online 30 Dec 2015

Jia H, Ordóñez F, Dessouky MM (2007) Solution approaches for facility location of medical supplies for large-scale emergencies. Computers \& Industrial Engineering 52(2):257 - 276

Kalkman JP, de Waard EJ (2017) Inter-organizational disaster management projects: Finding the middle way between trust and control. International Journal of Project Management 35:889-899 
Koppenjan JFM, Klijn EH (2004) Managing uncertainties in networks: A network approach to problem solving and decision making. London; New York : Routledge, 2004.

Li X, Ramshani M, Huang Y (2018) Cooperative maximal covering models for humanitarian relief chain management. Computers \& Industrial Engineering 119:301 - 308

Manopiniwes W, Irohara T (2017) Stochastic optimisation model for integrated decisions on relief supply chains: preparedness for disaster response. International Journal of Production Research 55(4):979-996

Margaret B T, Marilyn M H (2006) "bureaucracy, meet catastrophe" : Analysis of the tsunami disaster relief efforts and their implications for global emergency governance. International Journal of Public Sector Management (2):204

Martinez AJP, Stapleton O, Wassenhove LNV (2011) Field vehicle fleet management in humanitarian operations: A case-based approach. Journal of Operations Management 29(5):404 - 421, special Issue on Field Research in Operations and Supply Chain Management

Mavrotas G (2009) Effective implementation of the $\epsilon$-constraint method in multi-objective mathematical programming problems. Applied Mathematics and Computation 213(2):455 $-465$

Moreno A, Alem D, Ferreira D, Clark A (2018) An effective two-stage stochastic multi-trip location-transportation model with social concerns in relief supply chains. European Journal of Operational Research 269(3):1050 - 1071, URL http://search.ebscohost.com/login. aspx?direct=true\&db=eoh\&AN=1707672\& site=eds-live\&authtype $=i p$, shib\&custid $=$ s9815128

Moreno A, Munari P, Alem D (2019) A branch-and-benders-cut algorithm for the crew scheduling and routing problem in road restoration. European Journal of Operational Research 275(1):16 - 34, URL http://www.sciencedirect.com/science/article/pii/ S0377221718309299 
Moreno A, Munari P, Alem D (2020) Decomposition-based algorithms for the crew scheduling and routing problem in road restoration. Computers Operations Research 119:104,935, DOI https://doi.org/10.1016/j.cor.2020.104935, URL http://www.sciencedirect.com/ science/article/pii/S0305054820300526

Moynihan D (2008) Learning under uncertainty: Networks in crisis management. Public Administration Review (2):350

Muggy L, Heier Stamm JL (2020) Decentralized beneficiary behavior in humanitarian supply chains: models, performance bounds, and coordination mechanisms. Annals of Operations Research 284(1):333, URL http://search.ebscohost.com/login.aspx? direct=true\&db=edssjs\&AN=edssjs . 9992D216\&site=eds - live\&authtype=ip, shib\& custid $=\mathrm{s} 9815128$

Muggy L, L Heier Stamm J (2014) Game theory applications in humanitarian operations: a review. Journal of Humanitarian Logistics and Supply Chain Management 4(1):4 23, URL http://search. ebscohost. com/login. aspx?direct=true\&db=edsemr\&AN= edsemr.10.1108. JHLSCM $.07 .2013 .0026 \&$ site=eds - live\&authtype=ip, shib\&custid= s9815128

Nagurney A, Flores EA, Soylu C (2016) A generalized nash equilibrium network model for post-disaster humanitarian relief. Transportation Research Part E: Logistics and Transportation Review 95:1 - 18, DOI https://doi.org/10.1016/j.tre.2016.08.005, URL http://www.sciencedirect.com/science/article/pii/S1366554516303283

Nagurney A, Salarpour M, Daniele P (2019) An integrated financial and logistical game theory model for humanitarian organizations with purchasing costs, multiple freight service providers, and budget, capacity, and demand constraints. International Journal of Production Economics 212:212 - 226, DOI https://doi.org/10.1016/j.ijpe.2019.02.006, URL http://www.sciencedirect.com/science/article/pii/S0925527319300544

Nolte IM, Martin EC, Boenigk S (2012) Cross-sectoral coordination of disaster relief. Public Management Review 14(6):707 - 730 
Noyan N, Kahvecioglu G (2018) Stochastic last mile relief network design with resource reallocation. OR Spectrum 40(1):187 - 231, URL http://search.ebscohost.com/ login aspx?direct=true\&db=eoh\&AN=1697223\&site=eds-live\&authtype=ip, shib\& custid=s9815128

Noyan N, Balcik B, Atakan S (2016) A stochastic optimization model for designing last mile relief networks. Transportation Science 50(3):1092 - 1113, URL http: //search. ebscohost. com/login. aspx?direct=true\&db=bth\&AN=117300041\& site=eds-live\&authtype=ip, shib\&custid=s9815128

Paul JA, Zhang M (2019) Supply location and transportation planning for hurricanes: A two-stage stochastic programming framework. European Journal of Operational Research 274(1):108 - 125, URL http://search.ebscohost.com/login.aspx?direct=true\&db= eoh\&AN=1750420\&site=eds -1 ive\&authtype=ip, shib\&custid=s 9815128

PCV (2014) Information request 00001414. http:/ /www.veracruz.gob.mx/proteccioncivil/sistemade-portales-de-obligaciones-de-transparencia/. Accessed online 16 Jan 2014

Pradhananga R, Mutlu F, Pokharel S, HolguÃn-Veras J, Seth D (2016) An integrated resource allocation and distribution model for pre-disaster planning. Computers \& Industrial Engineering 91:229 - 238

Quarantelli EL (1988) Disaster crisis management: A summary of research findings. Journal of Management Studies (Wiley-Blackwell) 25(4):373 - 385, URL http://search.ebscohost. com/login. aspx?direct=true\&db=bth\&AN=4554605\& site=eds-live\&authtype=ip, shib\&custid=s9815128

Rezaei-Malek M, Tavakkoli-Moghaddam R, Zahiri B, Bozorgi-Amiri A (2016) An interactive approach for designing a robust disaster relief logistics network with perishable commodities. Computers \& Industrial Engineering 94:201 - 215

Rodríguez-Espíndola O, Albores P, Brewster C (2018a) Decision-making and operations in disasters: challenges and opportunities. International Journal of Operations \& Production Management 38(10):1964-1986 
Rodríguez-Espíndola O, Albores P, Brewster C (2018b) Disaster preparedness in humanitarian logistics: A collaborative approach for resource management in floods. European Journal of Operational Research 264(3):978 - 993

Rodríguez-Espíndola O, Chowdhury S, Beltagui A, Albores P (2020) The potential of emergent disruptive technologies for humanitarian supply chains: the integration of blockchain, artificial intelligence and 3d printing. International Journal of Production Research 0(0):121, DOI 10.1080/00207543.2020.1761565, URL https://doi.org/10.1080/00207543. 2020.1761565, https://doi.org/10.1080/00207543.2020.1761565

Santos JR, Herrera LC, Yu KDS, Pagsuyoin SAT, Tan RR (2014) State of the art in risk analysis of workforce criticality influencing disaster preparedness for interdependent systems. Risk Analysis 34(6):1056-1068

Sarma D, Bera UK, Das A (2019) A mathematical model for resource allocation in emergency situations with the co-operation of ngos under uncertainty. Computers \& Industrial Engineering 137:106,000

Scolobig A, Prior T, Schröter D, Jörin J, Patt A (2015) Towards peoplecentred approaches for effective disaster risk management: Balancing rhetoric with reality. International Journal of Disaster Risk Reduction 12:202 - 212, URL http://search.ebscohost. com/login. aspx?direct=true\&db=edselp\&AN= S2212420915000084\&site=eds-live\&authtype=ip, shib\&custid=s9815128

Seaberg D, Devine L, Zhuang J (2017) A review of game theory applications in natural disaster management research. Natural Hazards: Journal of the International Society for the Prevention and Mitigation of Natural Hazards p 1, URL http://search.ebscohost.com/login.aspx?direct=true\&db=edssj.s\&AN= edss js. 32525429\&site=eds-live\&authtype=ip, shib\&custid=s9815128

SEGOB (2006) Manual de organización y operación del Sistema Nacional de Protección Civil. http://www.secofi-sniim.gob.mx/sicia/ProteccionCivil.pdf. Accessed online 20 March 2018 
Takeda MB, Helms MM (2006) "Bureaucracy, meet catastrophe": Analysis of the tsunami disaster relief efforts and their implications for global emergency governance. International Journal of Public Sector Management 19(2):204-217

Takeda Margaret B, Helms Marilyn M (2006) "bureaucracy, meet catastrophe" : Analysis of the tsunami disaster relief efforts and their implications for global emergency governance. International Journal of Public Sector Management 19(2):204 - 217, URL http: //search. ebscohost. com/login. aspx?direct=true\&db=edsemr\&AN=edsemr .10 . 1108.09513550610650446\&site=eds-live\&authtype=ip, shib\&custid=s9815128

Thompson KM, Duintjer Tebbens RJ (2016) Framework for optimal global vaccine stockpile design for vaccine-preventable diseases: Application to measles and cholera vaccines as contrasting examples. Risk Analysis 36(7):1487-1509

Tofighi S, Torabi S, Mansouri S (2016) Humanitarian logistics network design under mixed uncertainty. European Journal of Operational Research 250(1):239 250, URL http://search.ebscohost. com/login. aspx?direct=true\&db=edselp\&AN= S0377221715008152\&site=eds-live\&authtype=ip, shib\&custid=s9815128

Toyasaki F, Arikan E, Silbermayr L, Falagara Sigala I (2017) Disaster relief inventory management: Horizontal cooperation between humanitarian organizations. Production and Operations Management 26(6):1221-1237, DOI 10.1111/poms.12661, URL https:// onlinelibrary.wiley.com/doi/abs/10.1111/poms.12661, https://onlinelibrary. wiley.com/doi/pdf/10.1111/poms. 12661

Velasquez GA, Mayorga ME, Cruz EAR (2019) Prepositioning inventory for disasters: a robust and equitable model. OR Spectrum: Quantitative Approaches in Management 41(3):757, URL http://search. ebscohost. com/login. aspx?direct=true\&db=edssjs\& AN=edss j s. 2AB76BD2\&site=eds -1 ive\&authtype=ip, shib\&cust $i d=s 9815128$

Zhang J, Liu H, Yu G, Ruan J, Chan FT (2019) A three-stage and multi-objective stochastic programming model to improve the sustainable rescue ability by considering secondary disasters in emergency logistics. Computers \& Industrial Engineering 135:1145 - 1154 


\section{APPENDIX}

The appendix is a section including mathematical notations, extra results, tables or figures that were referred to in the main text. The resources introduced in this section can help improve the understanding about the implications of the research.

Additional data and results. For the location of facilities, a set of shelters and distribution centers based on information from authorities and official guidelines were included. Candidate shelters and distribution centers are depicted in Figures 11 and 12, respectively.

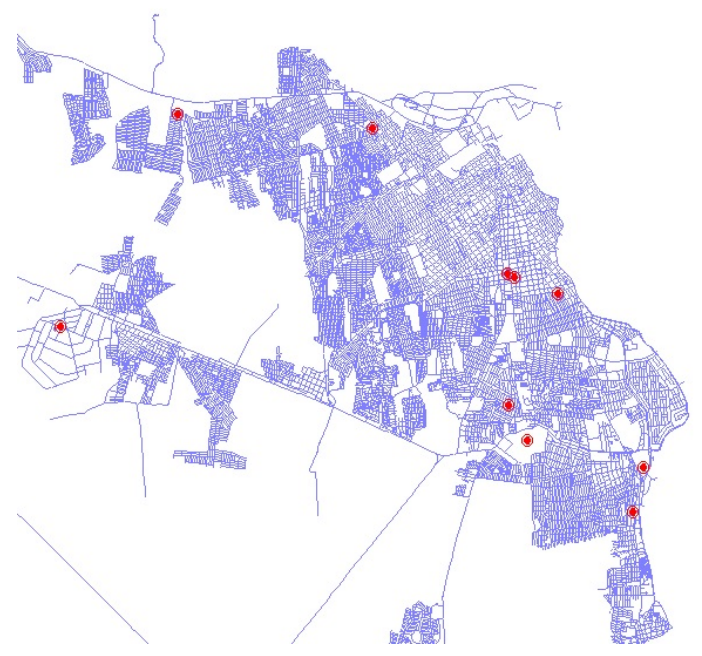

Figure 11: Location of possibles candidates a distribution center. (Source: Author's own elaboration) 


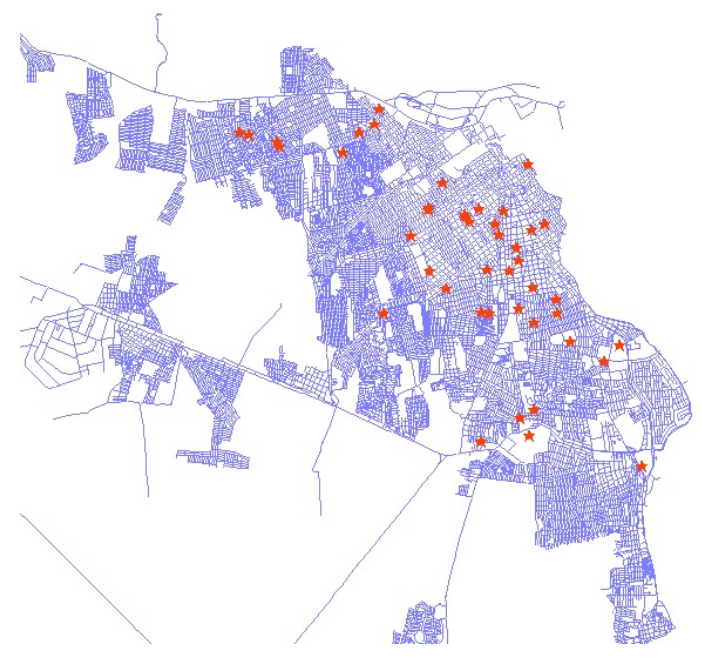

Figure 12: Location of possibles candidates a shelter. (Source: Source: Author's own elaboration)

Figure 13 shows the relative trade-off between the two objective functions, risk and cost. The axes are given in relative values. Negative variations indicate reduction, whereas positive variation indicate increase. We highlight the solution given by iteration 6 of the $\epsilon$-constraint method in which we see that it is possible to improve the overall relief assistance by almost $17 \%$ at the expense of less than $14 \%$ in the logistics costs. 


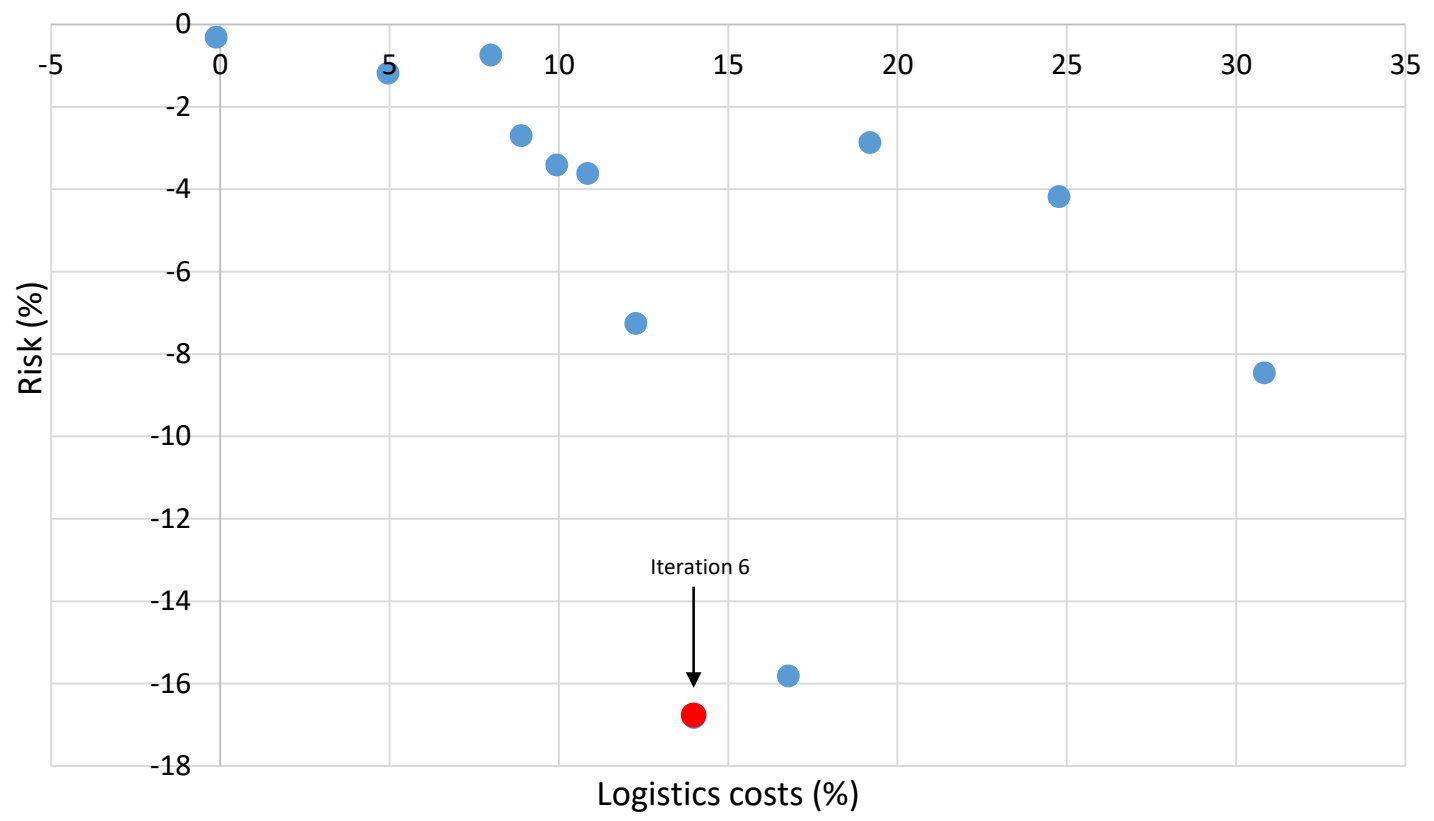

Figure 13: Trade-off between risk and cost for our case-study. The solution of the iteration 6 of the $\epsilon$-constraint method is highlighted in red.

Figure 14 shows the overall number and type of vehicles used to satisfy the victims needs for all the iterations and scenarios. As expected, there is a clear trend in using more small and medium-sized vehicles as the financial budget becomes more flexible. This result is particularly evident in scenarios with a larger number of victims and more overall resources, e.g., scenarios 15, 18, and 21. Apparently, there is an opposite trend in selecting large vehicles, as suggested by Figure 14. The reason is that more service-oriented solutions tend to use smaller vehicles to reach the increasing number of shelters. This is also related to the agencies activated, as larger agencies are deployed for cheaper solutions with larger vehicles, whereas other agencies provide smaller vehicles in service-oriented solutions. Helicopters are adopted to perform relief distribution in scenarios $5,6,7$, and 12 , because these vehicles are considerably more expensive and have more limited reach, so it seems they are only used when absolutely necessary. 

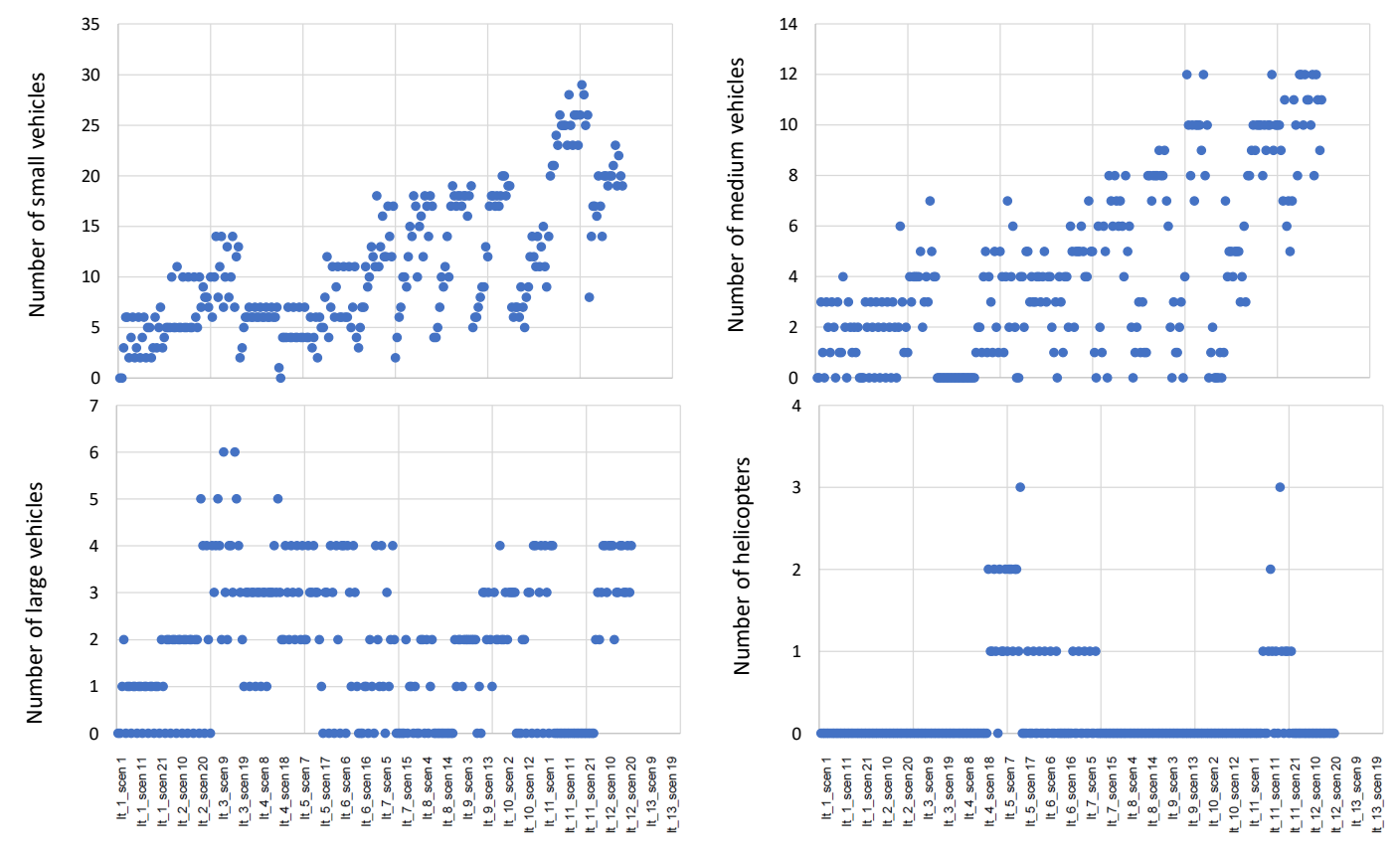

Figure 14: Number of small, medium and large vehicles, and helicopters for all the 13 iterations and 21 scenarios.

Despite the fact that some studies support claims that relief organizations usually prefer a homogeneous fleet of vehicles (Martinez et al, 2011), our results show that a heterogeneous fleet composed of small and medium-duty vehicles is more often used in most scenarios. The most diverse fleets were obtained in iterations 5,6 , and 7 for those scenarios with a small number of each type of vehicles, e.g., scenarios 4, 7, 10, 13, and so forth. Therefore, the heterogeneous fleet was deemed necessary to maintain a reasonable service level. The amount of aid transported for each mode follows the same rationale than the number of trips/vehicles, and for this reason, we now focus on the statistics behind these decision variables. Although medium vehicles are substantially more often used than large ones, both modes carry out a similar quantity of overall relief aid. On average, small vehicles transport approximately three times more relief goods than medium and/or large ones. On the other hand, helicopters transport a negligible quantity of aid in comparison to the other modes. Even when its capacity is more efficiently used in iteration 12 and scenario 16, its load corresponds to less than $20 \%$ of the small and medium vehicles' loads combined. 